\title{
Teoria Informacional e a Seleção de Relatores na Câmara dos Deputados
}

\author{
Fabiano Santos \\ Acir Almeida
}

\section{INTRODUÇÃO}

$\mathrm{O}$

s primeiros meses do ano de 1997 foram marcados por forte tensão entre os partidos da coalizão de apoio ao presidente Fernando Henrique Cardoso. Ao longo dos dois primeiros anos do mandato do presidente, várias reformas constitucionais foram aprovadas, mas uma, em especial, chamava a atenção de parlamentares do governo e da oposição: a emenda que aboliu o monopólio estatal na área de telecomunicações. O novo marco regulatório do setor dependia da tramitação e aprovação de pelo menos duas ou três proposições legislativas importantes, a principal delas sendo a Lei Geral de Telecomunicações, enviada em fins de 1996. Imediatamente, o Partido do Movimento Democrático Brasileiro - PMDB e o Partido da Frente Liberal - PFL, donos das duas maiores bancadas da Câmara dos Deputados, começaram a travar intensa disputa para indicar o relator da matéria - o PMDB sugerindo o nome do deputado Alberto Goldman, do Partido da Social Democracia Brasileira - PSDB de São Paulo, e o PFL, o nome de Paulo

\footnotetext{
*Versões preliminares deste trabalho foram apresentadas no IV Encontro Nacional da Associação Brasileira de Ciência Política - ABCP, em julho de 2004, e no XXIX Encontro Anual da Associação Nacional de Pós-Graduação e Pesquisa em Ciências Sociais ANPOCS, em outubro de 2005. Agradecemos a Wanderley Guilherme dos Santos e a um dos pareceristas de Dados pelos seus comentários.
}

DADOS - Revista de Ciências Sociais, Rio de Janeiro, Vol. 48, nº 4, 2005, pp. 693 a 735. 
Bornhausen, de Santa Catarina. Uma das fórmulas imaginadas para diluir o conflito foi a de dividir o projeto em três partes, o que desagradou o ministro Sérgio Motta, principal formulador da nova política. Finalmente, a complexidade da lei permitiu ao presidente da Câmara, deputado Luís Eduardo Magalhães, do PFL da Bahia, instalar uma comissão especial para apreciar o projeto, fato que conferiu ao governo e aliados a margem de manobra necessária para solucionar a contenda - a relatoria ficou com o deputado Goldman, cabendo ao Paulo Bornhausen presidir a comissão especial ${ }^{1}$.

Essa curta narrativa ilustra a importância que o cargo de relator de uma matéria sensível tem para o governo, partidos e o conjunto de parlamentares. Não obstante, e a despeito da recente evolução de estudos sobre o funcionamento do Congresso brasileiro, não se encontra disponível na literatura nenhum trabalho que discuta a importância da relatoria no processo decisório do Legislativo, tampouco que analise o processo de seleção de relatores nas comissões permanentes, seja da Câmara dos Deputados, seja do Senado Federal. Nosso objetivo neste artigo é dar um primeiro passo no preenchimento dessa lacuna, especificando o mecanismo através do qual o relator influencia a decisão da comissão e identificando (à luz daquele mecanismo) os determinantes da sua seleção. Esperamos, assim, estar contribuindo para a elucidação do processo decisório no Legislativo brasileiro.

O primeiro passo de nossa investigação foi a leitura atenta do Regimento da Câmara, mais especificamente dos artigos que definem os poderes do relator de comissão. Ao fim da leitura, e para nossa surpresa, deparamo-nos com uma espécie de puzzle: embora comumente tido como um dos atores-chave no processo decisório do Legislativo brasileiro, o relator não tem poderes formais suficientes para influenciar a decisão final da comissão. Isto porque, na votação final, uma maioria da comissão pode aprovar qualquer proposta alternativa ao parecer do relator. Como justificar, então, a percepção de que o relator é um "ator-chave"? Seria essa percepção incorreta? Nós argumentamos que o relator é um ator influente no processo decisório da comissão, mas que o fundamento da sua influência não é o seu poder formal (por exemplo, de seleção de emendas). A importância potencial do relator decorre, a nosso ver, de sua função de agente informacional da comissão, i.e., de sua delegação para coletar e compartilhar com seus pares informação a respeito das conseqüências de uma política pública específica. Como explicaremos mais adiante, o uso estratégico dessas prer- 
rogativas (especialmente a segunda) é o mecanismo através do qual o relator influencia a decisão final da comissão.

Nossa tese do relator como agente informacional da comissão ${ }^{2}$ está ancorada, do ponto de vista teórico, na literatura que analisa a tomada de decisão sob condição de incerteza e, em particular, nos trabalhos que analisam a escolha de fontes de informação por decisores racionalmente ignorantes. Nosso principal resultado, com base naquela literatura, é que um relator moderadamente contrário à proposta original é mais informativo do que um relator extremamente contrário, favorável ou neutro. Aplicando essa abordagem à seleção de relatores, na Câmara dos Deputados, durante a legislatura 1995-98, conseguimos explicar um fenômeno até então não adequadamente esclarecido: a designação de um número substancial de deputados da minoria oposicionista para relatar projetos do Executivo. A partir de dados originais relativos às características dos deputados, seus partidos e as comissões a que pertenceram, apresentamos forte evidência em favor da validade empírica da nossa explicação e, mais remotamente, da nossa tese a respeito da função do relator.

Organizamos este artigo da seguinte forma: na próxima seção, fazemos uma revisão da literatura sobre o problema da informação no Legislativo e como este problema se apresenta no caso da Câmara dos Deputados. Na terceira seção, analisamos o modo pelo qual a seleção e os poderes dos relatores encontram-se regulamentados, e propomos nossa interpretação informacional do poder do relator de influenciar a decisão final da comissão. Na quarta, discutimos como o problema informacional é um complicador para a aplicação da teoria do cartel legislativo ao caso brasileiro (Amorim Neto et alii, 2003), e como a capacidade explicativa desta pode ser melhorada adotando-se a nossa perspectiva. Ainda na quarta seção, derivamos algumas hipóteses de trabalho acerca dos determinantes da seleção de relatores de projetos do Executivo. Na quinta, testamos nossas hipóteses através de análise econométrica aplicada a uma base de dados originais contendo os deputados designados para relatar, nas comissões, as matérias do Executivo, durante o primeiro mandato do presidente Fernando Henrique Cardoso. Na sexta e última seção, concluímos com uma discussão dos nossos principais achados e com indicações dos potenciais desdobramentos desta agenda de pesquisa. 


\section{PROCESSO E COMPORTAMENTO LEGISLATIVO SOB A PERSPECTIVA INFORMACIONAL}

É de interesse coletivo que as decisões do Legislativo sejam bem informadas no que tange à relação entre a política adotada e seus resultados. Todavia, o legislador individual pouco ou nada sabe a respeito das conseqüências da maioria das políticas sobre as quais deve decidir. Como é possível, então, que o Legislativo chegue a uma decisão bem informada acerca de uma política qualquer quando a maioria dos seus membros não tem informação suficiente a respeito dos efeitos daquela política?

Esta questão motivou uma série de estudos sobre o Congresso norte-americano, que foram publicados na segunda metade da década de 1980 e que se revelaram seminais (Austen-Smith e Riker, 1987; e, principalmente, Gilligan e Krehbiel, 1987; 1989). Com a publicação, em 1991, de Information and Legislative Organization, de Keith Krehbiel, ganhou notoriedade a chamada "perspectiva informacional" dos estudos legislativos. Em contraposição direta à abordagem distributivis$\mathrm{ta}^{3}$, essa nova perspectiva enfatiza dois postulados que haviam sido abandonados pelos principais proponentes da primeira abordagem: o majoritário e o da incerteza. Pelo postulado majoritário, fica estabelecido que as decisões tomadas no Legislativo, nas comissões ou em plenário, têm como fundamento a vontade da maioria. O postulado da incerteza afirma que os legisladores decidem sem conhecer com certeza os resultados das políticas públicas que aprovam. O problema organizacional do Legislativo seria, então, o de garantir que as decisões sejam tomadas, em primeiro lugar, atendendo-se às preferências da maioria e, em segundo, com base na maior quantidade possível de informação, com vistas a reduzir a incerteza sobre os efeitos das políticas públicas. A redução da incerteza é, na perspectiva informacional, um dos bens coletivos fundamentais a ser alcançado através da estrutura institucional do Congresso, o que vale dizer que as instituições legislativas serão tanto mais eficientes quanto mais conduzirem os congressistas a adquirir e compartilhar conhecimentos especializados. Assegurar que as políticas aprovadas no Legislativo tenham por base o máximo de informação disponível e que essa informação tenha sido acessada pelo legislador mediano são a medida de sucesso de um Congresso bem organizado. 
De que maneira a contribuição de Krehbiel e Gilligan ajuda a entender o processo decisório interno do Legislativo no Brasil? Teria a perspectiva informacional alguma relevância para este caso? Em geral, as análises sobre o Congresso brasileiro dividem-se entre as que enfatizam o elemento distributivo no comportamento dos legisladores, oriundo de incentivos eleitorais de natureza personalizada, e as que privilegiam o poder de agenda dos líderes partidários e a influência do Poder Executivo na condução dos trabalhos das Casas legislativas ${ }^{4}$. Nosso propósito neste trabalho não é o de tomar posição no debate, embora esperemos que nossos achados possam contribuir para iluminar alguns de seus aspectos mais salientes. O importante a ressaltar da literatura é o fato de haver um consenso quanto à ausência de incentivos institucionais para a aquisição e distribuição de informação no interior do Legislativo brasileiro. Em outras palavras, não existiria o componente informacional no modo pelo qual o Congresso se encontra institucionalmente estruturado.

Na literatura, a estrutura de incentivos individuais com a qual se deparam os legisladores é a variável explicativa fundamental desta ausência do elemento informacional. No que tange aos incentivos individuais, o cerne do argumento diz respeito à inexistência de mecanismos endógenos de formação de especialistas em políticas públicas. Pelo menos quatro pontos são relevantes neste particular:

1) Os líderes partidários possuem fortes prerrogativas sobre a organização das atividades legislativas. Cabe a eles falar pela bancada no encaminhamento das votações, nomear e retirar membros das comissões, definir a pauta das votações no Colégio de Líderes, agilizar a tramitação de matérias através dos pedidos de urgência, e uma série de outras prerrogativas que acabam por esvaziar o poder das comissões temáticas, lócus, em última instância, no qual os parlamentares podem exercer alguma influência nas políticas públicas ${ }^{5}$;

2) Não existe na Câmara dos Deputados o sistema de senioridade pelo qual a indicação para postos de mando, notadamente nas comissões, é definida pelo número de anos de serviço no Legislativo ou em uma comissão permanente. A literatura sobre o Congresso norte-americano, desde o estudo seminal de Polsby (1968), é farta em exemplos que demonstram a relevância da seniority para a consolidação de carreiras dedicadas ao Legislativo, em geral, e em comissões especializadas, em particular ${ }^{6}$; 
3) Sobre carreiras legislativas também existe abundante material acerca dos reduzidos incentivos para a continuidade de mandatos legislativos. Os postos no Executivo, no âmbito federal, estadual e até municipal, seriam mais valorizados, o que levaria a taxas relativamente baixas de reapresentação no Legislativo ${ }^{7}$;

4) A sobrevalorização dos cargos no Executivo é, por sua vez, decorrência das prerrogativas deste Poder na condução do processo decisório. Os poderes orçamentários, especialmente o poder de contingenciar verbas, as áreas de iniciativa exclusiva, a capacidade de definir o regime de tramitação de matérias fundamentais, o poder de nomear e demitir dirigentes de agências públicas. Tudo isto compõe um enorme elenco de poderes políticos que favorecem os membros do Executivo no processo de definição de políticas públicas ${ }^{8}$.

Pelos motivos apontados anteriormente, pode-se dizer que os parlamentares brasileiros enfrentam um "problema informacional", ou seja, a estrutura institucional do Legislativo não gera incentivos para a produção endógena e sistemática de informação especializada. Ausentes os incentivos institucionais, também não é de se esperar que os parlamentares busquem soluções individuais para o problema dado que informação a respeito da relação entre políticas públicas e seus resultados é um bem coletivo. Isto posto, uma das motivações teóricas e empíricas para nossa análise refere-se ao que identificamos como um vazio na literatura sobre o Legislativo no Brasil, pois ao diagnóstico já explicitado dever-se-ia seguir a indagação natural: como os parlamentares brasileiros lidam com o problema informacional? De que maneira a incerteza em torno da votação de matérias cruciais é reduzida?

Uma resposta consistente com a experiência brasileira seria que o problema é resolvido via "partidarização" do governo - i.e., através da nomeação para o ministério de agentes dos partidos que apóiam o governo no Congresso. Cada um desses agentes, por ter o controle formal da informação (no caso, a expertise da burocracia) e deter a iniciativa de fato sobre certa área de políticas públicas, tem incentivo para tornar-se melhor informado a respeito da relação entre políticas específicas e seus resultados. Todavia, os ministros brasileiros estão longe de ser agentes perfeitos dos parlamentares ${ }^{9}$, o que nos leva a crer que, havendo conflito de interesse entre o governo e sua base parlamentar em torno de uma política pública qualquer, aquele tem amplo incentivo para fazer uso estratégico da sua vantagem informacional em benefício pró- 
prio e em detrimento dos interesses dos parlamentares. Em função disto, existe amplo terreno para que os parlamentares colham benefícios se não da produção, ao menos da coleta de informação alternativa à do governo.

A audiência pública é o mecanismo regimental mais diretamente voltado para a coleta de informação (alternativa à do governo) sobre as conseqüências de políticas públicas. Todavia, entendemos que existem duas limitações importantes para o uso efetivo deste mecanismo pelo parlamentar individual. Em primeiro lugar, o comparecimento a audiências públicas representa um alto custo de oportunidade para parlamentares, cujas agendas costumam estar cheias de compromissos mais prementes como, por exemplo, contatos com suas bases eleitorais. Em segundo lugar, mesmo que se supere o custo de oportunidade, resta ainda o custo (ou esforço) de se aprender as informações disponibilizadas através da audiência pública. Em função desses desincentivos, o mecanismo da audiência pública não é suficiente, per se, para resolver o problema de ação coletiva que enfrentam os parlamentares brasileiros na produção de informação ${ }^{10}$.

Nós identificamos na figura regimental do relator de comissão uma solução possível para esse problema. Nosso argumento é que o relator é um agente informacional da comissão, cuja função consiste na coleta e divulgação de informação sobre as conseqüências de uma política pública específica. Na próxima seção, nós desenvolvemos este argumento e especificamos os mecanismos através dos quais o relator cumpre tal função.

\section{RELATOR: SELEÇÃO, PODERES E INFLUÊNCIA}

O regimento interno da Câmara dos Deputados estabelece que toda proposição apreciada no âmbito das comissões permanentes deve ser inicialmente examinada por um relator (Câmara dos Deputados, 2004, art. 56). Em termos gerais, ao relator cabe proferir parecer sobre a matéria, sugerindo sua rejeição ou aprovação, esta última do texto original ou substitutiva que, a seu critério, pode ou não incorporar eventuais emendas apresentadas pelos demais membros da comissão.

A escolha dos relatores (e dos chamados relatores substitutos) é atribuição exclusiva do presidente da comissão, não havendo restrição alguma quanto a quais membros da comissão e por quantas vezes podem ser designados para relatar projetos (idem, art. 41$)^{11}$. O presidente, por 
sua vez, embora formalmente selecionado pela maioria dos membros da comissão, na prática deve seu cargo às lideranças partidárias. Isto porque o mesmo critério proporcional que se aplica ao preenchimento dos cargos da Mesa Diretora e das próprias comissões estende-se também à escolha da presidência destas ${ }^{12}$. $\mathrm{O}$ fato de o presidente escolhido não espelhar necessariamente a preferência do mediano (i.e., a possibilidade da distância entre seus respectivos pontos ideais ser significativa) é importante porque aumenta a chance de ser selecionado um relator cuja preferência é distinta da do mediano.

O relator tem a metade do tempo concedido à comissão para oferecer o seu parecer, variando esse tempo em função da natureza da matéria: cinco sessões, se o projeto tramita em regime de urgência; 10, quando o faz em regime de prioridade; e 40 nas ocasiões em que a tramitação ordinária é usada (idem, art. 52). É possível, entretanto, haver dilatação de prazo (por até a metade das sessões previstas inicialmente), a pedido do relator e com a concordância do presidente, exceto para o caso de tramitação em regime de urgência. Se o prazo é esgotado, a maioria dos membros da Comissão tem a prerrogativa de solicitar envio das matérias para plenário, pendente de parecer. Caso o relator não ofereça o parecer, o presidente da comissão deve designar outro deputado para fazê-lo.

Na elaboração do seu parecer, o relator tem total liberdade para emendar ou mesmo alterar o projeto original, podendo ou não levar em conta as preferências dos seus pares. Se o parecer é aprovado em todos os seus termos, é tido como parecer da comissão e enviado para a Mesa da Câmara para entrada na ordem do dia. Se ao parecer forem sugeridas alterações com as quais o relator concorde, é dado um prazo para a incorporação das modificações e para a oferta da nova redação. Se o voto do relator não for acatado pela maioria da comissão, caberá a um relator substituto preparar o novo texto nos termos aprovados pela maioria - tendo este também seu voto vencido, o presidente designa novo deputado para formular o parecer da comissão (idem, art. 57).

O que se pode concluir das regras de tramitação de matérias nas comissões? Fundamentalmente, que o relator não possui poder de agenda, isto é, a capacidade de definir quais propostas e quando vão a voto na comissão. Vejamos, em primeiro lugar, a questão do conteúdo das proposições. Um agenda setter pode selecionar as emendas que constarão da versão final do projeto, de forma a aproximá-lo tanto quanto possí- 
vel da sua alternativa mais preferida (ou ponto ideal), respeitando os limites definidos pela curva de indiferença do legislador mediano na comissão. Todavia, aos membros da comissão, no momento mesmo de votação do parecer do relator, é permitido oferecer alterações ao texto apresentado por ele. Conseqüentemente, o mediano é capaz de, em última instância, aprovar uma versão final do projeto que corresponda ao seu ponto ideal. Em segundo lugar, vejamos a questão dos prazos. Se as preferências do agenda setter e do mediano a respeito de uma proposta são tais que o que este aprova não é do interesse daquele, então o agenda setter pode agir estrategicamente não colocando a proposta em votação. Vimos, contudo, que o relator não tem esta prerrogativa - é perfeitamente possível para uma maioria da comissão forçar a apreciação de qualquer matéria no plenário desta nos casos em que o relator deixe de oferecer seu parecer dentro do prazo estabelecido.

À primeira vista, a inexistência de poderes formais que possibilitem ao relator influenciar a decisão da comissão parece contradizer a avaliação impressionista segundo a qual o relator é um ator-chave no processo decisório. Contudo, a nosso ver, o relator é, de fato, um ator estratégico no processo decisório intracomissão, não por conta, porém, de seus supostos poderes formais, tal como o poder de agenda, simplesmente porque ele não os tem. Alternativamente, nós propomos que o poder do relator decorre da sua função informacional ou, mais especificamente, da delegação que ele recebe da comissão para coletar e transmitir informação sobre o impacto da proposta que está relatando.

\subsection{Uma Rationale Informacional para a Influência do Relator}

Partindo do pressuposto de que os legislatores não têm certeza quanto às conseqüências das políticas públicas sobre as quais têm que decidir, pode-se, sob a perspectiva informacional, interpretar o relator como um agente da sua comissão cuja incumbência é coletar e compartilhar informação sobre o impacto de uma política específica. Para fundamentar teoricamente esta interpretação, fazemos uso da literatura sobre decisão sob condição de incerteza, mais especificamente dos trabalhos que dizem respeito à produção, transmissão e uso de informação, e que têm aplicação à questão substantiva que estamos analisando (Calvert, 1985; Crawford e Sobel, 1982; Dur e Swank, 2005; Krishna e Morgan, 2001; Milgrom e Roberts, 1986). 
Pela perspectiva informacional, a interação entre o relator e o legislador mediano da comissão pode ser descrita nos seguintes termos gerais:

1) O legislador mediano de uma comissão recebe uma proposta de política pública para aprovação cujas conseqüências não conhece com certeza;

2) O presidente da comissão seleciona um dos seus membros para relatar o projeto, i.e., para coletar informação a respeito das conseqüências da política proposta e recomendar uma decisão ao mediano da comissão. A qualidade da informação coletada pelo relator é uma função crescente do seu esforço, que não pode ser observado pelo legislador mediano. De posse das informações coletadas, o relator faz uma recomendação cuja qualidade depende do uso daquelas informações, o que também não pode ser observado pelo mediano;

3) Após tomar conhecimento do parecer do relator, o legislador mediano atualiza sua crença a respeito do impacto da política proposta e, então, decide sobre o projeto $^{13}$.

Mesmo reconhecendo que o grau de incerteza do legislador mediano varia positivamente com o grau de complexidade de cada proposta, em virtude do "problema informacional" do parlamentar brasileiro (definido na seção 2), é nossa premissa que o mediano tem elevada incerteza com relação à grande maioria dos projetos sobre os quais deve decidir ${ }^{14}$. A incerteza só não é um problema para o mediano sob condições muito especiais: quando seu ponto ideal coincide com o do autor da proposta e este é totalmente informado a respeito da política (Crawford e Sobel, 1982). Isto porque o autor, para evitar que o legislador mediano tome uma decisão "errada" devido à incerteza, tem tão mais incentivo para revelar sua informação privada quanto menor a distância entre o seu ponto ideal e o do mediano - e quanto maior esse incentivo, maior a credibilidade da informação revelada pelo proponente. Somente na situação extraordinária em que os pontos ideais são iguais e o autor da proposta é totalmente informado, o mediano decide sob condições informacionais ótimas. Ordinariamente, porém, ou os pontos ideais não são perfeitamente alinhados, levando o autor a omitir qualquer informação que leve o mediano a tomar uma decisão menos favorável àquele, ou o autor não é completamente informado, fazendo com que, mesmo quando os pontos ideais coincidem, ao mediano não seja revelada toda a informação relevante. Por isso, em geral, o mediano 
tem a possibilidade de aumentar a base informacional da sua decisão através do relator.

A delegação ao relator, por outro lado, não está livre de problemas de agência: existem os riscos de o relator não se esforçar o suficiente na produção de informação e de usar estrategicamente a informação produzida, em detrimento do mediano da comissão (Dur e Swank, 2005). O primeiro risco diz respeito à qualidade da informação; o segundo, à qualidade da recomendação. No que tange à qualidade da informação produzida, como esta depende do nível de esforço que o relator está propenso a dispender, não é certo que ele produzirá a melhor informação possível (pressupondo aversão a esforço). Muito embora nem o nível de esforço exercido pelo relator nem a qualidade da informação produzida por ele possam ser observados pelos membros da comissão, estes podem se basear em características observáveis do relator para inferir aqueles. Uma dessas características é a preferência do relator. A partir de um modelo de seleção de "agentes coletores de informação" dentre um grupo de indivíduos com preferências heterogêneas, Dur e Swank (idem) demonstram que indivíduos muito enviesados ou a favor ou contra uma proposta (tomando como referência o ponto ideal do decisor) têm menor incentivo para se esforçar na coleta de informação. Isto porque, em função de suas fortes crenças a respeito das conseqüências da proposta, é baixa a probabilidade de eles mudarem sua recomendação diante da descoberta de uma informação relevante. Assim, quanto mais enviesado for o relator escolhido, menor a expectativa do mediano da comissão em relação à qualidade da informação utilizada pelo relator para fazer sua recomendação. Adicionalmente, destacamos duas outras características: expertise e grau de instrução. Um legislador com conhecimento especializado sobre a matéria precisará coletar menos informação e, além disso, dispenderá um esforço bem menor para aprender uma informação nova ${ }^{15}$. Um legislador com alto grau de instrução, mesmo sem conhecimento especializado sobre a matéria, muito provavelmente terá mais facilidade (do que um com menor grau de instrução) para aprender a informação nova. Portanto, no que diz respeito à capacidade do relator de produzir informação de qualidade, a preferência dos membros da comissão é, primeiro, por parlamentares especialistas na matéria e, segundo, por parlamentares com grau de instrução elevado.

Considere-se agora a qualidade da recomendação. Dada a qualidade da informação produzida, a menos que os pontos ideais do relator e do 
mediano coincidam, aquele tem incentivo para ser estratégico na sua recomendação, omitindo informação relevante de forma a induzir o mediano a decidir por uma proposta que seja a mais próxima possível do ponto ideal daquele e não deste ${ }^{16}$. Em que medida a recomendação do relator, mesmo que enviesada, pode ser informativa para o mediano da comissão? Considerando que a recomendação do relator é uma reação à proposta original, então é possível que aquela seja informativa para o mediano na medida em que sirva, senão como contraponto, ao menos como complemento à informação contida na proposta original (Krishna e Morgan, 2001; Milgrom e Roberts, 1986). Assim sendo, um relator que seja enviesado contra a proposta original é mais informativo do que um que seja ou enviesado a favor ou neutro, porque tem mais incentivo para coletar e revelar informação que contradiga a informação originalmente revelada pelo autor da proposta. Porém, como argumentamos anteriormente, relatores com viés extremo contra a proposta são menos informativos do que relatores com viés moderado, porque não é crível que a recomendação daqueles seja baseada em informação de qualidade. Portanto, o mediano da comissão tem a expectativa de que a recomendação de um relator moderadamente contrário à proposta original seja "melhor" (no sentido de ser mais informativa) do que a de um relator extremamente contrário, favorável ou neutro.

Por fim, se o mediano não tiver a expectativa de que o parecer do relator escolhido pelo presidente da comissão é baseado em informação de qualidade, então não o utilizará para rever suas crenças a respeito das conseqüências da política sob exame, decidindo assim apenas com base nas suas crenças originais, o que pode ser desfavorável para o presidente da comissão. Por isso, ao escolher um relator, o presidente tem incentivo para levar em conta a preferência e a incerteza do mediano ${ }^{17}$. Isto implica que, em equilíbrio, o presidente seleciona um relator cuja proposta (i.e., parecer) faz parte do conjunto de alternativas passíveis de serem aprovadas pelo mediano, e tem a menor distância em relação ao seu ponto ideal (do presidente).

Em suma, o mecanismo através do qual o relator pode influenciar a decisão da comissão é o uso estratégico de informação que é cara aos legisladores. Este é, a nosso ver, o principal atrativo da relatoria para quem a exerce. Do ponto de vista dos demais membros da comissão, esse é um preço aceitável considerando-se o ganho informacional e a alternativa de dispender tempo e recursos valiosos na coleta de infor- 
mação. Todavia, isso não implica necessariamente que esta delegação para o relator seja um mecanismo eficiente (no sentido paretiano) de coleta de informação - este tipo de avaliação está além do escopo deste trabalho. Por ora, esperamos ter demonstrado que essa delegação é, pelo menos, uma solução de equilíbrio possível.

\section{TEORIA DO CARTEL E SELEÇÃO DE RELATORES: UMA ÓTICA INFORMACIONAL}

Nesta seção, utilizamos nossa interpretação para identificar os determinantes da seleção de relatores para projetos de interesse do Executivo, durante o primeiro governo de Fernando Henrique Cardoso (1995-98). A opção por aquele governo foi motivada pela constatação de uma aparente anomalia: embora sua base de apoio na Câmara dos Deputados tivesse funcionado como um cartel legislativo (Amorim Neto et alii, 2003), para vários projetos de interesse do Executivo foram designados relatores de partidos de oposição. Como demonstraremos adiante, através da ótica informacional, a designação de relatores de oposição, embora seja um complicador para o funcionamento do cartel, não é inconsistente com a sua existência.

Faz-se necessário, primeiro, estabelecer de maneira precisa a noção de cartel legislativo ou parlamentar (idem). Um cartel parlamentar existe quando o presidente (da República), mediante acordos de concessão de postos ministeriais a membros de partidos representados no parlamento, obtém, em troca, o apoio de uma maioria formada por tais partidos para a aprovação de sua agenda no Legislativo. É típico, neste caso, que cada agremiação seja um ator pivotal, no sentido de que seu abandono da coalizão implica a perda da condição de maioria do cartel. Além disso, e em decorrência do pressuposto dos atores pivotais, faz parte do acordo a concessão de algum poder de veto para os partidos membros do cartel, quanto à substância e ao timing de envio das matérias a serem votadas no plenário. Por último, é pressuposto na definição de cartel parlamentar que os membros da maioria monopolizam os postos relevantes do processo decisório da Assembléia, o que assegura a confecção e aplicação de procedimentos, formais ou informais, através dos quais o poder de veto dos partidos membros é imposto. Este último passo é importante, pois um cartel funciona em dois estágios. No primeiro, que poderia ser chamado de estágio negativo, os membros do cartel negociam a agenda decisória entre si, cada qual deixando claros os limites do que é ou não passível de acomodação. No se- 
gundo estágio, o estágio positivo, o cartel "impõe" a agenda resultante sobre o restante da Assembléia, seja mediante instrumentos legais que lhe conferem vantagens procedimentais, seja por intermédio da extração de disciplina partidária. Interessa-nos apenas o segundo estágio, ou seja, a capacidade do cartel para implementar sua agenda ${ }^{18}$.

$\mathrm{Na}$ aplicação da teoria do cartel ao caso brasileiro, Amorim Neto et alii não incorporam dois elementos que, a nosso ver, podem dificultar seriamente o funcionamento do cartel na implementação de sua agenda legislativa. O primeiro é institucional: os autores não levam em consideração que postos-chave do processo decisório na Câmara, tal como presidências das comissões permanentes, são sistematicamente controlados pela oposição, em virtude do critério proporcional de alocação de cargos. O segundo é comportamental: os autores não especificam como o cartel lida com o problema da indisciplina partidária entre os seus membros, o que se faz necessário especialmente porque ele continha partidos pouco disciplinados (PMDB, Partido Trabalhista Brasileiro - PTB e, a partir de abril de 1996, o Partido Progressista Brasileiro $\mathrm{PPB})^{19}$. Como argumentaremos adiante, o controle da presidência de comissões permanentes pela oposição e a baixa taxa de fidelidade partidária dentro do cartel criaram dificuldades para que a liderança do cartel fizesse valer a sua agenda no Legislativo - e o mecanismo através do qual aqueles dois fatores tiveram efeito foi a relatoria de comissão.

Quais seriam as implicações da teoria do cartel para a seleção de relatores de projetos do Executivo? Por aquela teoria, espera-se que praticamente todos os relatores de projetos do Executivo sejam membros do cartel. A razão é simples: são os projetos que mais interessam à liderança do cartel que, por isto, tem incentivo para mobilizar seus membros com vistas a controlar postos-chave no processo decisório, tal como a relatoria. Porém, não é o que se observa durante os anos de 1995 e 1998 : na verdade, deputados de oposição foram selecionados em $23 \%$ das designações feitas nas comissões permanentes. Este percentual inesperadamente alto de relatores de oposição pode ter decorrido simplesmente do controle da presidência de algumas comissões pela oposição. De fato, nas comissões presididas pelo cartel, apenas 13,5\% das designações recaíram sobre deputados da oposição, contra 64,3\% nas presididas pela oposição. Note-se, porém, que o cartel, por ser maioria, pode, sempre que lhe interessar, fazer uso do recurso de urgência legislativa para votar imediatamente qualquer projeto no plenário (Câmara dos Deputados, 2004, art.155), frustrando, assim, uma eventual tenta- 
tiva do presidente da comissão de aproximar, por intermédio do relator, a proposta do Executivo do seu ponto ideal (do presidente). Em vista desse recurso, como explicar, então, o elevado percentual de relatores de oposição nas comissões controladas pela oposição? A evidência não mostra diferença significativa na freqüência com que o cartel solicitou urgência para seus projetos após a designação de relatores de oposição, o que descarta a possibilidade de comportamento não-estratégico por parte dos presidentes de comissão (i.e., deles terem feito suas escolhas sem levar em conta a reação do cartel) ${ }^{20}$. Portanto, a elevada parcela de relatorias obtidas pelos partidos de oposição $(64,3 \%)$, nas comissões por eles presididas, parece-nos inconsistente com o esperado pela teoria do cartel ${ }^{21}$.

Enfim, a teoria do cartel, tal como aplicada ao caso brasileiro, não explica satisfatoriamente a elevada freqüência de deputados de oposição que foram designados para relatar projetos do Executivo no primeiro governo de Fernando Henrique. É nossa proposta que, sob a ótica informacional, e levando-se em consideração os elementos institucional e comportamental anteriormente mencionados, a elevada freqüência de relatores de oposição pode ser explicada a partir da lógica majoritária da teoria do cartel. Vejamos como.

Suponha-se que o ponto ideal do mediano de uma comissão seja suficientemente afastado do da liderança do cartel (ou seja, do Executivo). Então, sempre que o Executivo enviar para a Câmara um projeto de lei (PL) sob a jurisdição daquela comissão, ele terá incentivo para ser estratégico na justificativa da sua proposta, i.e., para omitir qualquer informação que, embora relevante para o mediano da comissão, leve este último a tomar uma decisão menos favorável àquele. Nestas condições, o mediano pode se beneficiar da seleção de um relator enviesado contra a proposta, i.e., cujo ponto ideal tenha localização oposta ao do Executivo (em relação ao mediano), exatamente porque tal relator tem incentivos para investir na coleta de informações que demonstrem que a proposta do Executivo é "ruim". Em outras palavras, a indicação de um opositor do cartel seria uma maneira do legislador mediano reduzir sua incerteza a respeito das conseqüências da política proposta pelo Executivo.

É razoável supor que o mediano de cada comissão era um membro do cartel, uma vez que este detinha a maioria, e a composição das comissões costuma obedecer ao princípio da proporcionalidade. Não obs- 
tante, é igualmente razoável supor que existia, ao menos em algumas comissões, uma razoável distância entre os pontos ideais do mediano e da liderança do cartel. Isso porque, ao longo do primeiro mandato de Fernando Henrique Cardoso, o PMDB, partido pivotal na Câmara, sempre conviveu com dissidência em sua bancada, principalmente por conta da postura nacionalista e antiprivatizante por parte de lideranças importantes daquela agremiação. O mesmo pode-se dizer com relação ao PPB no que tange ao tema nacionalismo, e ao PTB, a políticas de cunho trabalhista.

Sabemos, ao mesmo tempo, que a liderança do cartel contava com dois instrumentos para lidar com a eventualidade de uma comissão "infiel": o controle da presidência da comissão e o recurso regimental da urgência legislativa. Através do controle da presidência da comissão, o cartel é capaz de frustrar a demanda por informação do seu titular mediano, não designando membros da oposição para relatar projetos do Executivo. Através do recurso da urgência, o cartel evita que um relator de oposição tenha tempo hábil para coletar informação ou mesmo fazer recomendação contra a proposta do Executivo. Como vimos, no entanto, por motivos regimentais, o cartel não pode ter o controle de todas as presidências de comissão. Quanto ao uso da urgência pelo cartel, é razoável supor que sua viabilidade depende da distância entre os pontos ideais do mediano do plenário e da liderança do cartel, pois, para distâncias suficientemente grandes, o mediano do plenário não aprova o recurso de urgência porque tem a expectativa de se beneficiar de informação eventualmente a ser produzida na comissão. Se isso é verdade, e na medida em que o mediano da comissão seja representativo do mediano do plenário, então exatamente quando o Executivo mais deseja usar a urgência, ou seja, quando um projeto seu é analisado por uma comissão "infiel", menor o incentivo do mediano do plenário para aprovar aquele recurso. Em função disso, achamos justificável analisar o processo decisório no interior da comissão ignorando a possibilidade do uso da urgência pelo cartel.

Em resumo, portanto, a designação de relatores da oposição para projetos do Executivo depende da existência simultânea de duas condições: falta de coesão do cartel e controle da presidência da comissão pela oposição. Vejamos de forma mais detida como essas duas condições operam através de uma ótica informacional. 
Quando o ponto ideal do legislador mediano na comissão praticamente coincide com o do Executivo, este tem incentivo para revelar àquele toda a informação que possui a respeito do resultado esperado da política. Como, por isso, resta pouca ou nenhuma informação adicional a ser coletada ${ }^{22}$, a relatoria é irrelevante no que diz respeito à sua capacidade de influenciar a escolha do mediano. Nesta situação, nenhum parlamentar tem incentivo para exercer a relatoria, e o presidente da comissão é indiferente em relação a quem designar. Pode-se argumentar, todavia, que a relatoria é uma oportunidade para se obter outros benefícios como, por exemplo, exposição na mídia e o assédio de grupos de interesse. Se isso é verdade, e na medida em que estes eventuais benefícios superem o custo de relatar, haverá demanda pelos parlamentares para exercer a relatoria. Havendo demanda, o presidente da comissão tenderá, então, a usar sua prerrogativa de escolha para beneficiar parlamentares de seu próprio partido ou aliados. No entanto, a nosso ver, é bastante duvidoso que esses eventuais benefícios representem uma motivação sistemática e independente daquela salientada neste trabalho, i.e., a influência sobre políticas públicas. Portanto, quando o ponto ideal do mediano da comissão é praticamente igual ao do Executivo, é mais provável que o posicionamento do parlamentar em relação ao cartel não afete a probabilidade de ele ser designado relator de projetos do Executivo, independentemente do tipo do presidente da comissão, se de oposição ou não.

Apenas no caso de o legislador mediano na comissão não estar alinhado com o Executivo e, por conseguinte, este tiver incentivo para fazer uso estratégico da sua informação privada, a escolha do relator é estratégica. Se os pontos ideais do presidente da comissão e do Executivo coincidirem, então este claramente se beneficiará do poder de seleção daquele, no sentido que é selecionado um relator cuja proposta será a mais próxima possível do ponto ideal do Executivo, dentre as passíveis de aprovação pelo mediano. Mas se o presidente da comissão não estiver alinhado com o Executivo (i.e., ele pertence à oposição), o relator escolhido terá um viés contrário à proposta (ou seja, também será da oposição), e esse viés será tão maior quanto maior for a distância entre os pontos ideais do mediano e do Executivo (dado o grau de incerteza do mediano), e quanto maior a distância entre os pontos ideais do presidente da comissão e do mediano. Todavia, este efeito sobre o viés do relator escolhido, da distância entre o presidente e o mediano, é moderado pelo problema de credibilidade sofrido por parlamentares "extre- 
mistas", de forma que presidentes de comissão "extremistas" têm incentivo para designar um relator de oposição moderado.

O que esta lógica implica em termos da base informacional do mediano? Se o mediano e o Executivo estão alinhados, então este revela toda a sua informação e aquele toma uma decisão totalmente informada. Quando o mediano não está alinhado com o Executivo, mas o presidente da comissão está, este seleciona como relator um deputado com viés favorável ao Executivo e, por isso, não é possível para o mediano tomar uma decisão totalmente informada. Já no caso de um presidente de comissão não-alinhado com o Executivo, é designado um relator com fortes incentivos para coletar e divulgar informação que contradiga o Executivo, aumentando assim a base informacional da decisão do mediano. Porém, a decisão do mediano será totalmente informada se e somente se o presidente da comissão (e, por decorrência, o relator designado) for suficientemente enviesado contra o Executivo.

\subsection{Hipóteses}

Voltamo-nos agora à especificação das implicações observáveis que podem ser extraídas dos argumentos anteriores. Note-se que, como nosso objetivo é testá-las usando uma amostra relativa a uma circunstância específica (relatorias de projetos do Executivo durante o primeiro governo de Fernando Henrique Cardoso), as hipóteses serão especificadas tendo em mente esse objetivo.

A variável crítica de nossa análise é o viés do deputado em relação à preferência do cartel. Porém, a relação entre aquela variável e a freqüência com que o deputado é designado para relatar projetos do cartel depende de dois condicionantes: a existência de divergência entre o mediano da comissão e a liderança do cartel, e o tipo do presidente da comissão, se agente do cartel ou não. Mais especificamente, quando e somente quando as preferências do mediano e do cartel são diferentes, o posicionamento do deputado em relação ao cartel afeta a probabilidade de ele ser designado relator de projeto do Executivo. Esse efeito, por sua vez, depende do tipo do presidente da comissão. Se o presidente da comissão é um agente do cartel, então deputados cujas preferências são mais próximas do cartel são designados com maior freqüência. Então, nossa primeira hipótese é que:

H1: Se e somente se a preferência do mediano da comissão é diferente da do cartel, e se a presidência da comissão pertence ao cartel, então a 
probabilidade de o deputado ser designado relator de um projeto do Executivo aumenta com o seu viés a favor do projeto.

Se o presidente da comissão é da oposição, então deputados com viés moderadamente contrário ao Executivo devem ser designados com maior freqüência do que deputados neutros ou favoráveis, devido ao maior incentivo dos primeiros para contradizer o Executivo. Por outro lado, deputados com viés extremo contra o Executivo também devem ser designados com menor freqüência, porque não é crível para o mediano que eles investirão na coleta de informação de qualidade. Assim, nossa segunda hipótese é que:

H2: Se e somente se a preferência do mediano da comissão é diferente da do cartel, e se a presidência da comissão pertence à oposição, então a probabilidade de o parlamentar ser designado relator de um projeto do Executivo é maior quando ele é moderadamente enviesado contra a proposta, e menor quando é ou extremamente contrário ou neutro ou a favor.

Como argumentamos, dois fatores importantes para a qualidade da informação são o estoque de conhecimento do relator sobre a matéria a ser relatada e, alternativamente, a sua capacidade de aprender sobre ela. Qualquer que seja o tipo do presidente da comissão, do conjunto de parlamentares que ele considera potenciais candidatos em função de critérios ideológicos e partidários, esperamos que ele dê preferência, primeiro, a um especialista e, segundo, a um não-especialista com educação superior. Porém, também neste caso, esperamos que a relação desvaneça quando a preferência do mediano for similar à do Executivo, devido à inexistência de demanda por informação. Assim, nossa terceira e última hipótese é:

H3: Se e somente se a preferência do mediano da comissão é diferente da do cartel, parlamentares especialistas sobre a matéria têm maior probabilidade de serem designados relatores do que parlamentares não-especialistas com educação superior. Estes, por sua vez, têm maior probabilidade de serem designados do que parlamentares sem especialização nem educação superior.

\section{ANÁLISE EMPÍRICA}

\subsection{Dados e Método de Análise}

Para testar nossas hipóteses, construímos um banco de dados contendo informações sobre todos os deputados que exerceram mandato du- 
rante a legislatura 1995-98, seus partidos, comissões permanentes a que pertenceram, participações em votações nominais, e número de vezes que foram designados para relatar projetos do Executivo ${ }^{23}$. A unidade de análise é a tétrade deputado-semestre-partido-comissão. Decidimos criar múltiplos casos a partir do mesmo deputado em função da variação longitudinal de uma série de aspectos relevantes para nossa análise, a saber: filiação partidária, taxa de fidelidade partidária, e comissão temática a que pertenceu o deputado. O uso do semestre, e não do ano legislativo, visa a capturar o máximo possível da potencial variação daqueles aspectos - apenas o ano legislativo de 1998 não foi dividido em dois, por causa da baixa atividade legislativa no segundo semestre (número baixo de votações nominais relevantes, de trocas de partido e de trocas de comissões). Incluídos na "amostra" estão todos os deputados e suplentes que ou exerceram o mandato por pelo menos mais da metade de um semestre legislativo ou foram designados relatores de pelo menos um PL do Executivo apresentado na legislatura em pauta. As únicas exceções são os deputados que compuseram a Mesa Diretora da Câmara, que foram excluídos porque, devido aos seus cargos, não são considerados candidatos a relator. A partir desses critérios, se todos os deputados que inauguraram a legislatura 1995-98 tivessem exercido todo o seu mandato, se nenhum tivesse mudado de partido, e todos tivessem pertencido a uma e apenas uma comissão temática por semestre legislativo, então o número total de casos da amostra seria $3.542^{24}$. A amostra efetiva, no entanto, contém apenas 1.967 tétrades deputado-semestre-partido-comissão. Este menor número deve-se principalmente ao fato de algumas comissões não terem recebido, durante alguns semestres, nenhum projeto do Executivo para relatar ${ }^{25}$.

A variável dependente é o número de relatorias de projetos do Executivo computadas em cada tétrade. Nós restringimos a amostra a projetos apresentados na Câmara dos Deputados, pelo Executivo, durante a legislatura 1995-98, e para os quais ao menos um relator foi designado em alguma das comissões permanentes (à exceção da Comissão de Constituição, Justiça e Redação). Originalmente, identificamos um total de 146 PLs que obedeceram a estes critérios. Destes, excluímos 18 cujas matérias consideramos claramente irrelevantes do ponto de vista político-partidário ${ }^{26}$. Para os 128 PLs restantes, houve 166 designações de relatores nas comissões de mérito. Deste conjunto, excluímos 12 designações de deputados que eram suplentes da comissão ${ }^{27}$. Após esta seleção, o número total de designações de deputados para relatar pro- 
jetos do Executivo nas comissões permanentes, durante os anos de 1995 a 1998, ficou em 154. A Tabela 1 apresenta a distribuição de freqüência desta variável.

Tabela 1

Distribuição de Freqüência do Número de Designações para

Relatar Projetos do Executivo nas Comissões Permanentes,

Câmara dos Deputados, 1995-98

\begin{tabular}{c|c|c}
\hline $\begin{array}{c}\text { Número de Desig- } \\
\text { nações }\end{array}$ & $\begin{array}{c}\text { Freqüência } \\
\text { Absoluta }\end{array}$ & $\begin{array}{c}\text { Freqüência } \\
\text { Relativa (\%) }\end{array}$ \\
\hline 0 & 1.834 & 93,24 \\
1 & 117 & 5,95 \\
2 & 13 & 0,66 \\
3 & 1 & 0,05 \\
4 & 2 & 0,10 \\
\hline Total & $\mathbf{1 . 9 6 7}$ & $\mathbf{1 0 0}$ \\
\hline
\end{tabular}

Fonte: Câmara dos Deputados (www.camara.gov.br).

Nota: A unidade de análise é a tétrade deputado-semestre-partido-comissão.

As hipóteses listadas na seção 4.1 foram testadas através de um modelo de regressão binomial negativo, que é apropriado para variáveis de contagem, tal como o número de relatorias ${ }^{28}$. É comum dados de contagem apresentarem sobredispersão, ou seja, variância condicional maior que a média condicional. Se a sobredispersão não é levada em conta, o modelo tende a predizer contagens de valor zero com freqüência significativamente menor que a observada. $\mathrm{O}$ modelo binomial negativo inclui um parâmetro adicional (alfa) que mede o grau de sobredispersão dos dados e, na presença desta, lida com a subpredição de zeros através do aumento da variância condicional, sem alterar a média condicional. Todavia, como a amostra tem uma incidência muito grande de valores zero (veja Tabela 1), é bastante provável que mesmo o modelo binomial negativo apresente subpredição de zeros. Em face disto, estimamos uma versão deste modelo, chamada "inflacionada de zeros" (Zero Inflated), que corrige o impacto do excesso de zeros através da redução da média condicional por um fator correspondente à proporção de zeros, estimada através de um modelo binário (Logit ou Probit) da probabilidade de um zero ser observado na amostra (Cameron e Trivedi, 1998; Long 1997, cap. 8; Zorn, 1998).

De um ponto de vista substantivo, nossa modelagem do excesso de zeros difere da habitual. O pressuposto mais comum na literatura é que o 
excesso de zeros decorre de alguma diferença qualitativa (desconhecida do analista) entre os sujeitos da amostra, e que implica probabilidade um de se observar valor zero para uma parte considerável dos casos (Long, 1997, cap. 8; Zorn, 1998). No nosso problema específico, equivale pressupor que haveria dois grupos (desconhecidos) na amostra: um composto por deputados com probabilidade zero de serem designados relatores, e outro por deputados com probabilidade positiva. Porém, como nossa amostra exclui todos os casos em que tenha havido alguma impossibilidade prática de o deputado obter uma relatoria (por exemplo, porque estava licenciado ou não pertencia à comissão correspondente), aquele pressuposto não se aplica. Na verdade, o excesso de zeros na nossa amostra decorre tanto do relativamente pequeno número de projetos do Executivo, quanto da nossa definição da unidade de análise (que multiplica o número de deputados por semestre legislativo, partido e comissão). Em função disto, o número de zeros não apenas é inflado como também varia por semestre legislativo e comissão ${ }^{29}$. Então, ao invés de pressupor a existência de uma diferença qualitativa entre os deputados, nós modelamos a ocorrência de zeros diretamente, como função da probabilidade, definida a posteriori, de ocorrência de zero relatorias em cada caso da amostra.

Nossa definição da unidade de análise sugere, à primeira vista, a violação do pressuposto de independência entre os deputados da mesma díade comissão-semestre. Isto porque, dado o número de projetos distribuídos a uma comissão específica, e em um determinado semestre, o número de relatorias de um deputado titular da comissão deve estar negativamente correlacionado com o número de relatorias dos demais titulares da mesma comissão. No entanto, embora possivelmente uma conseqüência da forma como os dados foram organizados, este problema não decorre do processo de geração dos mesmos. A razão é que os presidentes de comissão escolhem os relatores sem conhecimento prévio do total de relatorias a serem distribuídas durante o semestre legislativo, uma vez que os PLs são apresentados e encaminhados às comissões ao longo do tempo, e não todos de uma só vez. Assim, o número de relatorias de cada titular da comissão pode ser concebido como independente do número de relatorias dos demais. Por outro lado, é provável que haja correlação entre o número de relatorias do mesmo deputado em semestres próximos. Esta potencial correlação é levada em conta no modelo mediante a utilização de erros-padrão robustos (a fórmula tradicional de Huber-White) com clusteres definidos por deputado. 


\subsection{Mensuração}

Os conceitos utilizados na formulação das hipóteses foram operacionalizados conforme se segue.

Distância do cartel é a nossa proxy para o viés do deputado em relação à agenda do cartel. Ela mede a distância entre a ideologia do cartel e a do partido do deputado. Para computar esta variável, primeiro definimos o posicionamento dos partidos parlamentares ao longo do eixo esquerda-direita, a partir do nosso julgamento, informado pela literatura e pelo senso comum. A Figura 1, a seguir, ilustra o posicionamento dos partidos e seus respectivos valores ao longo daquele eixo ${ }^{30}$. A partir dos valores assim determinados, nós definimos a localização do cartel no eixo como a média dos valores dos partidos da coalizão, ponderados pelos seus respectivos tamanhos de bancada dentro da coalizão. Com esta operacionalização, a localização do cartel no eixo é igual a 1,5, em 1995, e 2,5, a partir de 1996 (quando o PPB é incorporado ao cartel). Por fim, nós definimos que o valor de Distância do cartel é igual a zero para os deputados dos partidos que integram o cartel, o que na prática significa considerar a coalizão de governo como um partido único.

Fidelidade da comissão é a nossa proxy para o grau de divergência entre o mediano da comissão e a liderança do cartel, na forma da mediana da taxa de fidelidade ao cartel dos titulares da comissão. A taxa de fidelidade ao cartel de cada deputado foi calculada por semestre legislativo, sendo igual ao número de vezes que o deputado seguiu, em votações nominais relevantes ${ }^{31}$, o voto da liderança do governo, menos o número de vezes em que não seguiu, dividido pelo total de votações relevantes em que participou. Fidelidade da comissão tem um mínimo teórico de -1 (a maioria da comissão não seguiu a liderança do governo em nenhuma votação relevante) e um máximo de +1 (a maioria seguiu o go-

Figura 1

Posicionamento dos Partidos no Eixo Esquerda-Direita 1994

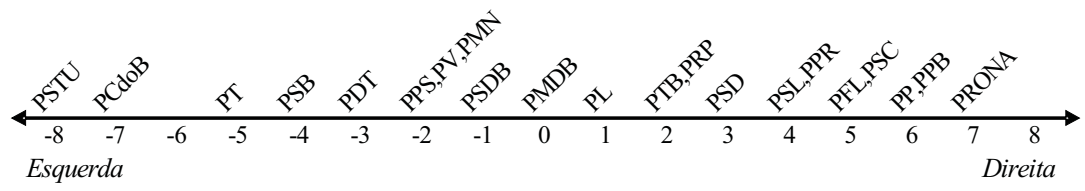


verno em todas as votações). Na amostra, o maior valor de Fidelidade da comissão é 0,920 (observado na Comissão de Finanças e Tributação CFT, no ano de 1998), e o menor é -0,295 (observado na Comissão de Trabalho, Administração e Serviço Público - CTASP, no primeiro semestre de 1996).

Não utilizamos a localização ideológica do partido do mediano da comissão para operacionalizar o grau de divergência entre este e a liderança do cartel porque o resultado seria praticamente uma constante, uma vez que o mediano pertencia ao PMDB na grande maioria das comissões. Consideramos a mediana da taxa de fidelidade uma boa aproximação do grau de divergência entre o mediano e a liderança do cartel por duas razões complementares. Primeiro, por causa da relação teórica esperada entre estes dois conceitos, qual seja, que heterogeneidade de preferências é condição necessária para infidelidade partidária. Segundo, porque devido à organização descentralizada e à multiplicidade de facções que compõem o partido mediano na Câmara, o PMDB, aquela relação teórica muito provavelmente também deve ser de suficiência entre os membros deste partido.

Oposição preside a comissão é uma variável indicadora com valor 1 quando o presidente da comissão não é de um partido membro do cartel, e valor zero quando o é. Os partidos que fizeram parte da coalizão majoritária de governo foram PSDB, PFL, PMDB, PTB e, a partir do primeiro semestre de 1996, o PPB.

Pelas primeira e segunda hipóteses, o efeito de Distância do cartel é condicionado por Fidelidade da comissão e por Oposição preside a comissão. Para testar essa relação de condicionalidade, incluímos no modelo interações de Distância do cartel com cada uma daquelas duas variáveis, separadamente e em conjunto. Mais especificamente, na primeira hipótese, a relação postulada é que Distância do cartel tem um efeito negativo sobre o número de relatorias do deputado, mas se e somente se $F i$ delidade da comissão for suficientemente menor que 1 e se Oposição preside a comissão for igual a zero. Pela segunda hipótese, o número de relatorias é uma função quadrática de Distância do cartel, mais especificamente uma parábola com concavidade voltada para cima (i.e., na forma de U invertido), mas se e somente se Fidelidade da comissão for suficientemente menor que 1 e se Oposição preside a comissão for igual a 1. Para testar a relação quadrática da hipótese 2, nós incluímos no modelo o quadrado de Distância do cartel, isoladamente, em interação com Oposi- 
ção preside a comissão, e em interação simultânea com esta variável e Fidelidade da comissão.

Especialista é uma variável indicadora igual a 1 se o deputado tem conhecimento especializado sobre algum tema pertencente à jurisdição de sua comissão, e zero se não tem. Por conhecimento especializado entendemos formação educacional ou experiência profissional. Assim, por exemplo, um deputado da Comissão de Economia, Indústria e Comércio - CEIC é considerado especialista se for graduado em Economia ou se for dirigente de uma grande empresa. Não-especialista com nível superior também é uma variável indicadora que assume valor 1 quando o deputado tem curso superior completo, mas não pode ser considerado um especialista em nenhum dos temas tratados pela sua comissão; caso contrário, o valor é zero. Pela hipótese 3 , esperamos que Especialista e Não-especialista com nível superior tenham ambas efeitos positivos, mas se e somente se Fidelidade da comissão for suficientemente menor que 1. Também esperamos que o efeito da primeira variável seja maior que o da segunda.

Incluímos no modelo outras variáveis para efeito de controle. A principal motivação para os controles provém da explicação alternativa à tese do cartel: assim como as presidências das comissões permanentes e outros cargos relevantes, as relatorias de projetos do Executivo podem ser distribuídas entre os partidos obedecendo o critério da proporcionalidade. Assim, espera-se que, quanto maior o tamanho da bancada do deputado, maior sua chance de ser designado relator. Por isso, nossa primeira variável de controle é Tamanho do partido, operacionalizada simplesmente como o percentual de membros titulares da comissão que pertencem ao partido do deputado. Ainda na linha de que as relatorias são alocadas a todos os partidos de acordo com seu tamanho, é razoável esperar que critérios intrapartidários de distribuição de benefícios sejam igualmente relevantes para todos os deputados. Dois critérios são potencialmente relevantes: a fidelidade do deputado ao seu partido e a sua senioridade no partido. Fidelidade ao partido foi calculada tal como a taxa de fidelidade ao cartel, só que levando em conta o voto da maioria do partido do deputado (e não o da liderança do cartel). Senioridade foi operacionalizada como Tempo de filiação ao partido, em anos, transformada para a escala logarítmica ${ }^{32}$. Os efeitos destas duas últimas variáveis, se existirem, devem ser positivos. 
Por fim, no que diz respeito à especificação do modelo binário, nós operacionalizamos a probabilidade de ocorrência de zero relatorias em cada caso da amostra a partir de duas variáveis: Probabilidade de seleção e $N$ o de relatorias da comissão. A probabilidade de o deputado ser selecionado aleatoriamente pelo presidente da comissão é simplesmente o inverso do número de titulares da sua comissão. O número de relatorias da comissão é simplesmente o total de designações feitas pelo presidente da comissão, no semestre e enquanto o deputado estava exercendo o mandato (e, portanto, era um candidato em potencial). A probabilidade de não ser observada ao menos uma relatoria de projeto do Executivo em qualquer tétrade deputado-semestre-partido-comissão é uma função decrescente da Probabilidade de seleção e do logarítmo de № de relatorias da comissão.

As estatísticas descritivas das variáveis independentes anteriormente definidas são apresentadas na Tabela 2.

Tabela 2

Estatísticas Descritivas das Variáveis Independentes

\begin{tabular}{l|c|c|c|c}
\hline & Média & Desvio-Padrão & Mínimo & Máximo \\
\hline Distância do cartel & 1,62 & 2,81 & 0 & 10,5 \\
Fidelidade da comissão & 0,722 & 0,166 & $-0,295$ & 0,920 \\
Oposição preside a comissão* & 0,189 & 0,391 & 0 & 1 \\
Especialista* & 0,486 & 0,450 & 0 & 1 \\
Não-especialista com nível superior* & 0,429 & 0,495 & 0 & 1 \\
Tamanho do partido & 15,9 & 7,2 & 2,0 & 30,8 \\
Fidelidade ao partido & 0,804 & 0,281 & $-0,944$ & 1 \\
Tempo de filiação ao partido $(\log )$ & 0,776 & 0,369 & 0 & 1,53 \\
Probabilidade de seleção & 0,029 & 0,009 & 0,020 & 0,05 \\
№ de relatorias da comissão $(\log )$ & 0,288 & 0,298 & 0 & 1,34 \\
\hline
\end{tabular}

Fonte: Câmara dos Deputados (www.camara.gov.br).

Nota: $\mathrm{N}=1967 ;{ }^{*}$ variáveis binárias.

\subsection{Resultados}

As estimativas do nosso modelo de regressão do número de designações para relatar projetos do Executivo são apresentadas na Tabela 3. Nós estimamos dois modelos, o primeiro com e o segundo sem as variáveis de controle para a explicação alternativa. Como os coeficientes do modelo binomial negativo não têm interpretação substantiva, nós 
avaliamos os efeitos substantivos das principais variáveis independentes através dos seus impactos na probabilidade prevista.

Tabela 3

Determinantes do Número de Vezes que o Deputado foi Designado

para Relatar Projetos do Executivo

1995-98

\begin{tabular}{|c|c|c|}
\hline & Modelo 1 & Modelo 2 \\
\hline \multicolumn{3}{|l|}{ Binomial Negativo } \\
\hline Distância do cartel & $-0,60 * *(2,95)$ & $-0,55^{*}(2,02)$ \\
\hline Distância do cartel $\times$ Fidelidade da comissão & $0,43^{* *}(2,59)$ & $0,62^{* *}(2,58)$ \\
\hline Distância do cartel $\times$ Oposição preside a comissão & $3,53^{* *}(2,41)$ & $3,95^{* *}(2,57)$ \\
\hline Distância do cartel $\times$ Oposição preside $\times$ Fidelidade da comissão & $-3,70^{*}(1,87)$ & $-4,21^{*}(2,04)$ \\
\hline Distância do cartel $\wedge 2$ & $0,03(1,23)$ & $0,00(0,07)$ \\
\hline Distância do cartel $\wedge 2 \times$ Oposição preside a comissão & $-0,43^{*}(2,31)$ & $-0,52 * *(2,58)$ \\
\hline Distância do cartel $\wedge 2 \times$ Oposição preside $\times$ Fidelidade da comissão & $0,43^{*}(1,75)$ & $0,54 *(2,02)$ \\
\hline Especialista & $4,06^{* *}(3,23)$ & $3,49^{* *}(2,63)$ \\
\hline Especialista $\times$ Fidelidade da comissão & $-4,85^{* *}(3,05)$ & $-4,26^{* *}(2,56)$ \\
\hline Não-especialista com nível superior & $3,83^{* *}(2,96)$ & $3,41^{* *}(2,55)$ \\
\hline Não-especialista com nível superior $\times$ Fidelidade da comissão & $-4,53^{* *}(2,78)$ & $-4,07^{* *}(2,41)$ \\
\hline Tamanho do partido & & $0,05^{* *}(3,37)$ \\
\hline Fidelidade ao partido & & $1,01^{* *}(2,96)$ \\
\hline Tempo de filiação ao partido (log) & & $0,43^{*}(1,79)$ \\
\hline Fidelidade da comissão & $4,05^{* *}(2,55)$ & $3,32^{*}(1,98)$ \\
\hline Oposição preside a comissão & $-3,12(1,10)$ & $-2,51(0,89)$ \\
\hline Oposição preside a comissão $\times$ Fidelidade da comissão & $3,35(0,91)$ & $2,64(0,72)$ \\
\hline Constante & $-4,43^{* *}(3,46)$ & $-3,59^{* *}(5,52)$ \\
\hline \multicolumn{3}{|l|}{ Logit } \\
\hline Probabilidade de seleção & $-55,15^{* *}(3,42)$ & $-58,97^{* *}(3,54)$ \\
\hline$N^{o}$ de relatorias da comissão $(\log )$ & $-3,18^{* * *}(6,95)$ & $-3,13^{* *}(6,72)$ \\
\hline Constante & $3,83^{* *}(6,19)$ & $3,82^{* *}(6,08)$ \\
\hline Parâmetro de dispersão (alfa) & 0,0 & 0,0 \\
\hline Log pseudo-likelihood & $-493,1$ & $-483,7$ \\
\hline Deviance pseudo- $R^{2}$ ajustado & 0,178 & 0,192 \\
\hline № de observações & 1967 & 1967 \\
\hline $\mathrm{N}^{\circ}$ de observações zero & 1834 & 1834 \\
\hline
\end{tabular}

Nota: A unidade de análise é a tétrade deputado-semestre-partido-comissão. Valores são coeficientes binomiais negativos inflacionados de zero e coeficientes logit, estimados através do módulo ZINB do Stata. Entre parênteses, o valor absoluto da respectiva estatística Z. Erros-padrão ajustados para clusteres por deputado.

Obs.: ${ }^{*} p<5 \%$ e ${ }^{* *} p<1 \%$, em teste unidirecional.

Em primeiro lugar, vejamos a adequação aos dados do modelo estatístico selecionado. A estimativa do parâmetro de dispersão (alfa) resultou igual a zero, o que nos permite concluir que os dados são equidis- 
persos (variância igual à média). Do ponto de vista prático, isto implica que as estimativas dos coeficientes do modelo binomial negativo equivalem às do modelo de contagem mais simples, o Poisson. Ademais, como os graus de liberdade são muito elevados neste caso, não há perda relevante de eficiência, o que torna os resultados destes dois modelos praticamente iguais ${ }^{33}$. Nossa opção pela versão "inflacionada de zeros" do modelo foi correta: encontramos forte evidência de que, de fato, o excesso de zeros decorre em boa medida da forma como definimos a unidade de análise (a tétrade deputado-semestre-partido-comissão): Probabilidade de seleção e o logarítmo de № de relatorias da comissão resultaram ambas com coeficientes negativos e altamente significativos. Pode-se concluir, então, que o modelo escolhido é adequado aos dados.

Avaliemos agora o ajuste aos dados das especificações dos modelos, tal como medido pelo Deviance pseudo- $\mathrm{R}^{2} .{ }^{34} \mathrm{O}$ segundo modelo logrou uma redução proporcional no erro de $19,2 \%$, redução esta apenas levemente maior que a alcançada pelo primeiro $(17,8 \%)$, sem as variáveis de controle. É necessário dizer, no entanto, que grande parte da redução do erro decorre da especificação do modelo binário - o modelo logit completo com o modelo binomial negativo contendo apenas a constante reduz o erro de predição em 14,1\%. À primeira vista, isto é uma indicação de que a capacidade preditiva das variáveis de interesse substantivo é baixa. Por outro lado, deve-se ter em mente que o excesso de zeros da variável dependente ou, em outras palavras, a raridade do fenômeno analisado, impõe severas restrições à sua adequada predição. Em função deste último aspecto, e tendo em vista inexistir conhecimento prévio a respeito da mesma variável dependente, não é possível ser conclusivo a respeito do ajuste dos modelos aos dados.

A evidência é consistente com o que postula a primeira hipótese? Pelos resultados obtidos, a estimativa do coeficiente linear de Distância do cartel é significativamente menor que zero (no nível de 5\%) ${ }^{35}$ somente quando o valor de Oposição preside a comissão é igual a zero, e o de Fidelidade da comissão é menor que 0,76 , no modelo 1 , e 0,26 , no modelo 2 , o que corrobora nossa expectativa de que essas duas variáveis têm efeito condicional. No entanto, no que diz respeito ao efeito condicionante desta última variável no segundo modelo, é muito baixo o valor limite observado $(0,26)$. Isto quer dizer que, mesmo quando o mediano é bastante infiel ao cartel (por exemplo, quando segue a liderança em menos da metade das votações), não se observa o efeito esperado de Distância 
do cartel, o que não é totalmente consistente com o postulado pela primeira hipótese. Para entender o porquê do menor valor limite encontrado no modelo 2, nós o reestimamos omitindo uma variável de controle por vez. Observamos, então, que a diferença de resultado decorre tão somente da presença de Tamanho do partido ${ }^{36}$. Pode-se, então, concluir que, quando o tamanho do partido do deputado na comissão é levado em conta, a evidência corrobora apenas em parte a hipótese 1.

Vejamos agora a evidência relativa à segunda hipótese. Os testes mostraram que, somente quando o valor de Oposição preside a comissão é igual a 1, e o valor de Fidelidade da comissão é menor que 0,76 e 0,80, nos modelos 1 e 2, respectivamente, a estimativa do coeficiente linear de Distância do cartel é significativamente maior que zero, e a estimativa do coeficiente do seu termo quadrático é significativamente menor que zero (ambas no nível de 5\%). Isto significa que a relação entre Distância do cartel e o número de relatorias têm a forma de um U invertido, mas com o lado esquerdo mais "íngreme" que o direito. Substantivamente, significa dizer que a probabilidade de o deputado ser designado relator de projeto do Executivo aumenta com o distanciamento deste do cartel, atingindo seu valor máximo antes da metade da distância entre o cartel e o partido de oposição mais afastado, para, então, diminuir conforme a distância aumente ${ }^{37}$. Em suma, deputados da oposição "moderada" têm maior probabilidade que os demais de serem designados relatores de projetos do Executivo quando a comissão é presidida pela oposição e o seu mediano não é muito fiel ao cartel. Concluímos, assim, que existe forte evidência em favor da hipótese 2.

Para avaliar o impacto substantivo de Distância do cartel, nós utilizamos o método de probabilidades previstas ${ }^{38}$. Este método consiste na estimação, para cada valor da variável independente selecionada, da probabilidade prevista do evento analisado ocorrer, quando os valores de todas as demais variáveis independentes são fixados a critério do analista. Nesta aplicação particular, estimamos, com base no modelo 2, a probabilidade prevista de o deputado ser designado ao menos uma vez, ao longo da legislatura 1995-98, relator de projeto do Executivo ${ }^{39}$. As estimativas foram calculadas como função de Distância do cartel e das variáveis mediadoras, Oposição preside a comissão e Fidelidade da comissão ${ }^{40}$, mantendo-se as demais variáveis do modelo fixas em suas respectivas médias, no caso das intervalares, e modas, no caso das categóricas. O Gráfico 1 ilustra os resultados. 


\section{Gráfico 1}

Impacto Substantivo de Distância do Cartel, para Valores Selecionados de Fidelidade da Comissão e por Tipo de Presidência da Comissão
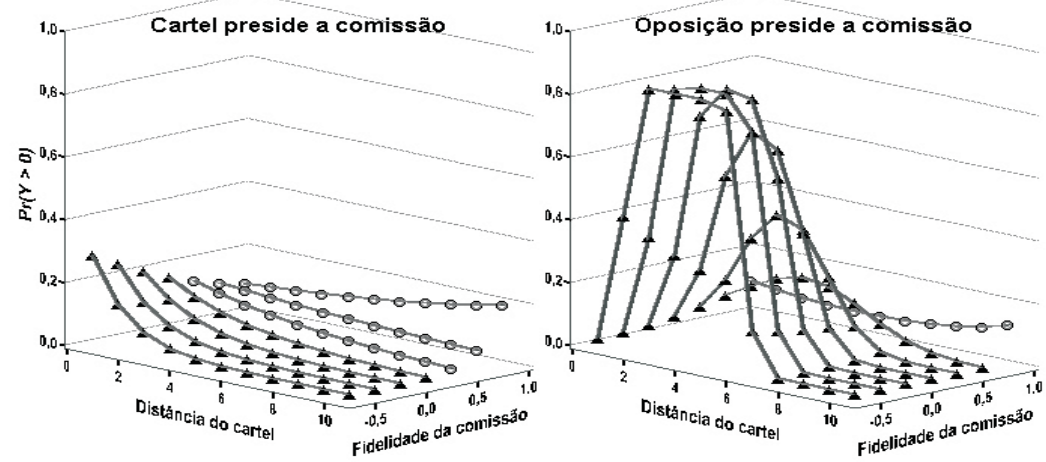

Nota: O eixo vertical representa a probabilidade estimada de o deputado ter sido designado ao menos uma vez para relatar projeto do Executivo, durante a legislatura 1995-98. Valores calculados a partir do modelo 2, com todas as demais variáveis fixadas em suas respectivas médias (se intervalar) ou modas (se categórica).

$\boldsymbol{\Delta}$ significativo a $5 \%$; O não significativo (teste unidirecional).

Note-se, no gráfico que ilustra o efeito de Distância do cartel quando a comissão é presidida por um membro da base do governo, que a relação não é estatisticamente significativa para valores de Fidelidade superiores a 0,25 . Já no gráfico que ilustra o efeito de Distância quando a comissão é presidida por um membro da oposição (e que corresponde à segunda hipótese), fica claro que, apenas quando Fidelidade é alta (maior que 0,75$)$, a relação não é estatisticamente significativa. O efeito quadrático pode ser claramente identificado neste último gráfico, sendo tão mais forte quanto menor o valor de Fidelidade da comissão. Note-se ainda que o máximo de cada curva é alcançado para um valor que, no eixo de Distância, corresponde à noção de oposição "moderada" (no caso, o valor 3).

É substancial o impacto de Distância do cartel sobre a probabilidade prevista do deputado obter pelo menos uma relatoria. No caso do cartel presidir uma comissão totalmente "infiel", i.e., cujo valor de Fidelidade é, por exemplo, 0 ,25, a probabilidade de um deputado da oposição moderada (Distância igual a 3) vir a ser designado relator é de apenas 0,05, contra 0,15 de um membro do cartel (Distância igual a zero). Este efeito 
é maior para níveis menores de fidelidade da comissão. No caso de a comissão ser presidida por um membro da oposição, o efeito é bem maior: quando Fidelidade é igual a 0,25, o aumento do valor de Distância, de zero para 3 , aumenta a probabilidade prevista de 0,03 para 0,66 ! Mesmo no caso de uma comissão pouco infiel, com Fidelidade igual a, digamos, 0,75 , aquele mesmo aumento implica um impacto na probabilidade prevista de 0,06 para 0,17.

No que diz respeito à terceira hipótese, os testes relativos às estimativas dos coeficientes de Especialista e Não-especialista com nível superior mostraram que ambas são significativamente maiores que zero (no nível de 1\%) nos dois modelos, porém somente para valores de Fidelidade da comissão não superiores a 0,71 , no modelo 1 , e 0,68 , no modelo 2 . Todavia, a evidência não permite rejeitar a hipótese nula de que não há diferença significativa entre as estimativas dos coeficientes totais, qualquer que seja o valor de Fidelidade. Ou seja, a evidência corrobora o efeito postulado do conhecimento prévio ou capacidade do parlamentar sobre a sua chance de ser designado relator de projeto do Executivo, mas indica que esta chance é igualmente afetada pelo fato de o deputado ser um especialista ou, não o sendo, ter nível superior. Avaliamos que, mesmo não encontrando apoio para a diferença postulada entre especialistas e não-especialistas com nível superior, a relação mais importante para a nossa tese foi devidamente corroborada, qual seja, que estes fatores têm efeito positivo e que este efeito existe somente quando há demanda informacional por parte do mediano da comissão. Portanto, é nossa avaliação que a hipótese 3 foi corroborada pela evidência, senão totalmente, ao menos em sua principal parte.

O efeito substantivo de Especialista e Não-especialista com nível superior é apresentado na Tabela 4. Como não há diferença significativa entre os coeficientes dessas duas variáveis, e por serem suas categorias mutuamente exclusivas, calculamos o impacto para o caso de uma ou outra ser verdadeira. Assim, por exemplo, quando Fidelidade da comissão é igual a zero, o fato de o deputado ser um especialista ou não-especialista com nível superior aumenta de 0,006 para 0,186 a probabilidade estimada de ele obter uma relatoria de projeto do Executivo. Este impacto diminui conforme Fidelidade aumenta, sendo, por exemplo, de 0,034 para 0,123 quando o valor desta variável é igual a 0,50 . Pela magnitude dos impactos observados, pode-se dizer que o efeito da expertise também é substancial. 
Tabela 4

Impacto Substantivo da Especialização Prévia e Conhecimento, para Valores Selecionados de Fidelidade da Comissão

\begin{tabular}{l|cccc}
\hline \multirow{2}{*}{ Não-especialista sem nível superior } & \multicolumn{4}{|c}{ Fidelidade da Comissão } \\
\cline { 2 - 5 } Especialista ou não especialista com nível superior & 0 & 0,25 & 0,50 & 0,75 \\
\hline Diferença (impacto) & 0,006 & 0,015 & 0,034 & 0,075 \\
\hline
\end{tabular}

Nota: Valores são probabilidades estimadas de o deputado ter sido designado ao menos uma vez para relatar projeto do Executivo, durante a legislatura 1995-98. Cálculos feitos com base no modelo 2, fixando-se as demais variáveis em suas respectivas médias (se intervalar) ou modas (se categórica). Impactos significativos no nível de 5\% (teste unidirecional) estão negritados.

Quanto às variáveis de controle, as estimativas dos seus respectivos coeficientes resultaram todas significativas e na direção esperada. Conforme aumentam ou o tamanho do seu partido na comissão ou sua taxa de fidelidade ao partido ou ainda seu tempo de filiação ao partido, maior a probabilidade de o deputado obter uma relatoria de projeto do Executivo. Os efeitos substantivos dessas variáveis sobre a probabilidade estimada de o deputado obter ao menos uma relatoria durante a legislatura estão ilustrados na Tabela 5. Para efeito de simplificação, para cada uma dessas variáveis nós apresentamos apenas seu impacto potencial máximo e seu impacto padrão médio ${ }^{41}$. Pelos valores da tabela, fica claro que, talvez com a exceção apenas de senioridade, essas variáveis produzem impactos substantivamente relevantes.

Tabela 5

Impactos Substantivos de Tamanho do Partido,

Fidelidade ao Partido e Senioridade no Partido

\begin{tabular}{l|c|c}
\hline & Impacto potencial máximo $^{\mathbf{a}}$ & Impacto padrão médio $^{\mathbf{b}}$ \\
\hline Tamanho do partido & $0,056 \rightarrow 0,184$ & $0,087 \rightarrow 0,118$ \\
Fidelidade ao partido & $0,019 \rightarrow 0,121$ & $0,089 \rightarrow 0,116$ \\
Tempo de filiação ao partido $(\log )$ & $0,074 \rightarrow 0,136$ & $0,099 \rightarrow 0,112$ \\
\hline
\end{tabular}

Nota: Valores são probabilidades estimadas de o deputado ter sido designado ao menos uma vez para relatar projeto do Executivo, durante a legislatura 1995-98. Cálculos feitos com base no modelo 2, fixando-se as demais variáveis em suas respectivas médias (se intervalar) ou modas (se categórica).

a Impacto decorrente do aumento do valor mínimo para o valor máximo da variável.

${ }^{\mathrm{b}}$ Impacto decorrente do aumento de um desvio-padrão da variável em torno da sua média.

Para testar a sensibilidade das estimativas do modelo à nossa medida da preferência dos parlamentares, nós reestimamos o modelo 2 utilizando uma medida alternativa de Distância do cartel, construída com 
base nas estimativas NOMINATE (Poole e Rosenthal, 1985) dos pontos ideais dos deputados, produzidas por Leoni $(2002)^{42}$. A nova medida equivale à diferença absoluta entre o valor da estimativa NOMINATE do deputado (de oposição) e a média ponderada da estimativa NOMINATE dos partidos do cartel. Constatamos apenas duas diferenças dignas de nota entre os resultados obtidos com a medida original e os obtidos com a alternativa. Primeiro, ocorreu uma redução do valor limite de Fidelidade da comissão a partir do qual o efeito de Distância do cartel é significativo e negativo (quando Oposição preside a comissão é igual a zero), de 0,26 para zero. Isto significa que, com a medida alternativa, a evidência em favor da hipótese 1 é ainda mais precária. A segunda diferença é o fato de a estimativa do coeficiente de Tempo de filiação ao partido deixar de ser significativa quando usamos a medida alternativa. De resto, não houve diferença nem nas conclusões substantivas, nem nos resultados estatísticos, o que nos permite concluir que o modelo é suficientemente robusto às duas medidas utilizadas. Por fim, não obstante nossa medida não ser capaz de capturar variações de preferência intrapartido, consideramos que, para os objetivos deste trabalho, ela é conceitualmente mais apropriada do que as estimativas NOMINATE, porque, neste caso específico, estas refletem mais o posicionamento (contra ou a favor) do deputado em relação ao governo, e menos a sua preferência por políticas (Leoni, 2002:382).

Portanto, achamos ser correto concluir que, tanto estatística quanto substantivamente, a evidência corrobora de forma mais que satisfatória nossa tese sobre a seleção de relatores, mesmo não encontrando total apoio para a primeira hipótese, e diante da pequena qualificação que fomos forçados a fazer com relação à hipótese 3. Especialmente importante é o fato da evidência ser fortemente favorável à nossa segunda hipótese, que é a implicação central da nossa explicação para a designação sistemática de deputados de oposição para relatar projetos de interesse do cartel.

\section{CONCLUSÃO}

Neste artigo, propusemos uma interpretação não-convencional do mecanismo através do qual o relator exerce influência sobre a decisão final da sua comissão. Ao invés de poderes formais, argumentamos que o relator tem um poder de fato, e que este consiste na possibilidade de fazer uso estratégico de informação que é cara para o mediano da co- 
missão. A função do relator é, a nosso ver, informacional - ele é uma espécie de advisor ad hoc dos seus pares.

Em favor da relevância da nossa tese, argumentamos que ela acrescenta capacidade explicativa a uma recente contribuição teórica a respeito de como o legislativo brasileiro operou durante o primeiro governo de Fernando Henrique Cardoso. Conforme acreditamos ter demonstrado, a teoria do cartel somente é capaz de explicar a designação sistemática de relatores de oposição para projetos de interesse do Executivo quando nossa perspectiva é adotada. Além de argumentos, apresentamos também evidência quantitativa de que a seleção de relatores para projetos do Executivo, durante o primeiro governo de Fernando Henrique Cardoso, obedeceu a padrões consistentes com a nossa perspectiva informacional. Constatamos que a seleção de relatores de oposição, se por um lado dependeu do tipo do presidente da comissão, por outro, refletiu as necessidades informacionais do seu mediano, uma vez que foi condicionada pela expectativa deste quanto à qualidade da recomendação feita pelo cartel e quanto à qualidade da informação que seria produzida pelos eventuais relatores.

Em nossa análise, olhamos apenas para um aspecto particular do processo de formulação de políticas públicas: a seleção de relatores nas comissões permanentes. Esta, no entanto, pode ser pensada como uma etapa de um jogo mais extenso, no qual as etapas que a precedem e que a sucedem são também fundamentais. No contexto específico que analisamos, anteriormente à seleção do relator existe a decisão do Executivo de qual política propor (ou não) e como. O Executivo pode decidir postergar, ou mesmo não apresentar, uma determinada política se tiver a expectativa de que a decisão final da comissão será desfavorável. Além disso, o Executivo tem a opção de encaminhar a matéria via medida provisória, evitando assim que seja examinada por uma comissão que espera encontrar dificuldades. Posteriormente à decisão da comissão, e a não ser que lhe tenha sido concedido poder terminativo, o "jogador" relevante é certamente o plenário da Câmara. Em que medida, então, o fato de a nossa análise ignorar essas outras etapas afeta a validade das nossas inferências?

No que diz respeito à decisão final do plenário, para que ela afete a seleção do relator, é necessário que os pontos ideais dos medianos da comissão e do plenário sejam suficientemente diferentes. No caso específico que analisamos, isto é mais provável ocorrer quando existe ou (1) 
um mediano infiel ao cartel na comissão e um fiel no plenário, ou (2) vice-versa. Note, porém, que, se o mediano da comissão é fiel ao cartel, então a relatoria não tem valor estratégico e, por isso, o grau da divergência com o mediano do plenário não afeta a seleção do relator. Então, o cenário (2) pode ser descartado como irrelevante. Quanto ao cenário (1), sabemos que, se o presidente da comissão é fiel ao cartel, então ele nunca escolhe um relator que induza o mediano da comissão a aprovar algo que seja desfavorável ao Executivo e, por conseguinte, ao mediano do plenário. Também neste caso, portanto, a seleção do relator não é afetada pela divergência entre a comissão e o plenário. Apenas quando o presidente da comissão é da oposição, a seleção do relator tenderá a ser afetada no sentido de incentivar o presidente a escolher um deputado mais favorável ao Executivo. A razão é que o presidente corre o risco do plenário ou retirar o projeto da comissão (via recurso de urgência) ou simplesmente ignorar o parecer da comissão. Em suma, se levada em conta a preferência do mediano do plenário, então nossa inferência a respeito da hipótese 2 não deve ser válida (apenas) na situação em que o mediano de plenário é fiel ao cartel e apenas nessa situação.

No que diz respeito à decisão do Executivo de quais projetos iniciar e como, ela implica que nossos resultados são condicionados ao conjunto de projetos que foram efetivamente apresentados. Isto significa que nossa análise sofre de um viés de seleção. A direção desse viés, porém, é conhecida: como é razoável supor que o Executivo encaminha PLs somente quando tem a expectativa de que a decisão da comissão não lhe será suficientemente desfavorável, então nossa estimativa da probabilidade de um deputado de oposição conquistar a relatoria de um projeto do Executivo está subavaliada - em outras palavras, nossa amostra na verdade ameniza o efeito que postulamos existir. Por isto, este aspecto não representa uma ameaça, mas sim um reforço, à validade das nossas inferências.

O que este artigo acrescenta ao atual estágio de análise do comportamento legislativo no Brasil? Basicamente, o trabalho avança ao ponderar a tese segundo a qual, uma vez montada uma coalizão majoritária de sustentação às políticas do Executivo, toda a agenda do Legislativo serviria aos propósitos do governo. Argumentamos que o "espírito da lei" proporcionalista que rege a representação partidária no país, espírito este ratificado no Regimento Interno da Câmara, assim como em suas práticas, produz efeitos importantes no processo decisório daquela Casa ao oferecer oportunidades para que deputados de oposição 
ocupem postos relevantes, como é o caso da relatoria de PLs. Nosso argumento serve também para mitigar as teses de acordo com as quais a suposta fragmentação de preferências e falta de disciplina partidária, conseqüências imaginadas da representação proporcional de lista aberta, tornam o trabalho da Câmara disperso e imprevisível. Procuramos mostrar que existem determinantes sistemáticos da escolha de relatores, mesmo sendo estes de oposição, e que tais determinantes podem ser definidos através de proposições logicamente consistentes e empiricamente testáveis.

As próximas etapas da pesquisa parecem-nos claras. É preciso, em primeiro lugar, estabelecer proposições teóricas que dêem conta do processo decisório do governo quando do envio ao Legislativo das matérias que sofrerão tramitação ordinária, passíveis, por isso, de serem relatadas por parlamentares oposicionistas. Em seguida, é necessário verificar o destino de tais matérias no restante de sua tramitação. Essa fase é crucial, pois indicará em que medida o componente proporcional de organização da atividade legislativa é importante, não apenas como princípio de representação e inclusão, mas também como mecanismo institucional responsável pela produção de efeitos sistemáticos sobre o status quo legal do Brasil.

(Recebido para publicação em novembro de 2005)

(Versão definitiva em dezembro de 2005) 


\section{Teoria Informacional e a Seleção de Relatores na Câmara dos Deputados}

\section{NOTAS}

1. Para boa análise do processo legislativo que transformou o status quo legal no setor de telecomunicações, ver Velasco Jr. (2005).

2. A idéia do relator como agente informacional da comissão aparece também em Montenegro (2004).

3. Para um resumo dessas duas vertentes, ver Shepsle e Weingast (1995).

4. No primeiro grupo, estão Ames (2000), Carvalho (2003), Pereira e Muller (2002) e Samuels (2003). No segundo, Figueiredo e Limongi (1999), Meneguelo (1999), Pessanha (1997) e Santos (2003). Para avaliação da aplicação dos modelos distributivo e informacional ao processo decisório da Câmara dos Deputados, ver Pereira e Muller (2000) e Ricci e Lemos (2004).

5. Ver Figueiredo e Limongi (1999), Meneguello (1998), Pereira e Mueller (2000) e Santos (2003).

6. A respeito dos cargos nas comissões, ademais, um forte incentivo contrário à permanência dos deputados como membros: o fato do mandato do presidente durar apenas um ano sem permissão de recondução (Câmara dos Deputados, 2004, art.39). São inúmeros os textos que chamam a atenção para a importância da senioridade no Congresso norte-americano - bons exemplos são Mayhew (1974), Fiorina (1977), Krehbiel (1991), Parker (1992), Shepsle (1979) e Weingast e Marshall (1983).

7. Sobre carreiras, ver Samuels (2003) e Santos (2003). Sobre os determinantes da reapresentação e reeleição no contexto brasileiro, ver Pereira e Rennó (2001).

8. Ver Pessanha (1997) e Figueiredo e Limongi (1999).

9. Principalmente porque os parlamentares não têm poder formal sobre a nomeação (nem demissão) do ministro, o que permite ao chefe do Executivo, quando este deseja obter o apoio daqueles, selecionar indivíduos que estejam na fronteira de indiferença dos parlamentares.

10. A audiência pública está prevista nos arts. 255 e 256 do regimento. Até onde sabemos, no entanto, não há trabalho acadêmico que tenha avaliado ainda a freqüência com que as comissões temáticas realizam audiências públicas acerca de temas relacionados com projetos sob sua apreciação. Também desconhecemos a existência de análises de como os parlamentares alocam seu tempo entre as diversas atividades legislativas (e extralegislativas).

11. Este não é o caso nas comissões especiais, em que é de praxe que a presidência e a relatoria sejam ocupadas pelos dois maiores partidos da Câmara.

12. Ver artigos 8, 27, e 39 do Regimento Interno, para a escolha dos membros da Mesa, preenchimento das comissões e eleição das presidências das comissões, respectivamente. O coeficiente da regressão linear do percentual de presidências de cada um dos partidos nos seus respectivos tamanhos é igual a 0,98 , evidenciando perfeita proporcionalidade.

13. Esta interação corresponde a um jogo de sinalização. Para uma introdução a respeito, ver Morrow (1994).

14. Na discussão que segue, por incerteza queremos dizer apenas "incerteza em relação a resultados". 
15. Isto não contradiz a premissa de que, regra geral, os parlamentares enfrentam um "problema informacional". A especialização, neste caso, é prévia, i.e., decorre ou da formação educacional ou da experiência profissional do parlamentar, e não da sua atuação sistemática na comissão (Santos, 2003:101).

16. Para efeito de simplificação, pressupomos que a informação pode ser omitida, mas não falsificada.

17. Conforme argumentado na seção anterior, o presidente não é livremente escolhido pela comissão, o que aumenta a chance da sua preferência ser distinta da do mediano da comissão.

18. Ao restringirmos nossa análise a projetos oriundos do Executivo, estamos pressupondo que aqueles já reflitam o poder de veto dos membros do cartel, "paridos" que foram pela coalizão de governo. Ou seja, consideramos que a agenda está dada com o envio de projetos pelo Executivo.

19. A respeito da taxa de disciplina, ver Nicolau (2000). Alternativamente à disciplina partidária, a agenda do cartel pode ser implementada usando-se "poderes extraordinários", tal como o poder de decreto do Executivo (Amorim Neto et alii, 2003:551). Como nossa amostra contém apenas Projetos de Lei - PLs, pode-se concluir que estamos analisando os casos em que a taxa de disciplina esperada pelo Executivo era suficientemente alta. Isto significa que a amostra selecionada torna mais difícil a demonstração do nosso argumento.

20. A análise incluiu apenas as comissões presididas pela oposição, e excluídos os projetos para os quais a oposição apoiou o pedido de urgência. O beta estimado da regressão Logit do pedido de urgência no tipo de relator não resultou significativo. Também observamos que a probabilidade do cartel solicitar a urgência para um projeto não aumentou com o número de comissões presididas pela oposição para as quais o projeto fora encaminhado. Para uma análise dos determinantes do uso da urgência, ver Pereira e Muller (2000).

21. Entendemos que este achado impõe uma forte qualificação à premissa de que "a existência e o funcionamento do sistema de comissões estão subordinados às preferências do Executivo" (Pereira e Muller, 2000:46).

22. Achamos razoável o pressuposto de que o Executivo é bem informado a respeito das políticas públicas que propõe.

23. Essas informações foram extraídas do sítio eletrônico da Câmara dos Deputados. O banco de dados pode ser obtido mediante solicitação, por e-mail, a qualquer um dos autores.

24. 3.542 casos $=(513$ deputados -7 membros da Mesa $) \times 7$ períodos legislativos.

25. Este foi o caso, por exemplo, da Comissão de Relações Exteriores, no ano de 1995. Existe ainda o caso da Comissão de Fiscalização Financeira e Controle, que não aprecia PLs. Excluímos também os casos de relatoria da Comissão de Constituição, Justiça e Redação, que normalmente não examina o mérito de projetos.

26. PLs que, como o 978/95, davam nomes a rodovias ou viadutos, e PLs que, como o 4505/98, concediam pensão especial a indivíduos.

27. Decidimos não incluir os suplentes de comissão no universo de potenciais relatores por causa da pouca freqüência com que estes foram designados. Evitamos, assim, um aumento excessivo do número de casos nulos da variável dependente. 
28. Para uma rápida introdução a modelos de contagem, ver Long (1997, cap.8).

29. A Comissão de Trabalho, Administração e Serviço Público designou 26 relatores no ano de 1998, mas apenas 11 ao longo de 1995. Por outro lado, a Comissão de Agricultura e Política Rural designou apenas um relator em cada um dos anos de 1995, 1996 e 1998.

30. Note-se que nosso ordenamento dos grandes partidos é igual ao utilizado por Amorim Neto et alii (2003).

31. Definimos uma votação como relevante se e somente se o seu Índice de Relevância de Carey - IRC for igual ou superior a 20. O IRC é igual a \% presente x [1- $1 \% \operatorname{sim}-\%$ não l] (Carey, 1998).

32. A transformação logarítmica de variáveis que expressam duração é usual. A razão é que o efeito marginal tende a ser menor para valores mais elevados da variável.

33. As estimativas binomiais negativas são menos eficientes que as Poisson porque o primeiro modelo estima um parâmetro (o alfa) a mais que o segundo.

34. Como não há consenso em torno de uma medida do ajuste de modelos não-lineares, nós decidimos utilizar o Deviance pseudo- $\mathrm{R}^{2}$ por ser a que melhor se aproxima dos pressupostos do $\mathrm{R}^{2}$ de um modelo linear. A respeito, ver Cameron e Windmeijer (1996).

35. Os níveis de significância utilizados nos testes de hipótese são todos unidirecionais.

36. Distância do cartel e Tamanho do partido são correlacionadas, porém não a ponto de sugerir que seus efeitos independentes não possam ser estimados com razoável precisão $(r=-0,49, p<0,001)$.

37. Pelos nossos cálculos, o ponto máximo é atingido quando Distância é aproximadamente igual a 3, o que é consistente com a noção de oposição "moderada".

38. Todas as probabilidades previstas foram calculadas utilizando o pacote Spost (Long e Freese, 2003).

39. Na verdade, estimamos a probabilidade $q$ de se observar zero relatorias na tétrade deputado-semestre-partido-comissão e, então, calculamos a probabilidade $p$ de o deputado obter ao menos uma relatoria durante toda a legislatura, da seguinte forma: $p=1-q^{7}$, onde a sétima potência representa o número de períodos legislativos.

40. Para Fidelidade, foram selecionados apenas múltiplos de 0,25 , sendo o mínimo -0,50 e o máximo, 1,0 .

41. O primeiro é o impacto sobre a probabilidade estimada decorrente do aumento da variável do seu valor mínimo para o seu máximo amostrais. Já o segundo, decorre do aumento de um desvio-padrão da variável em torno da sua média.

42. Agradecemos a Eduardo Leoni pela presteza com que disponibilizou seus dados para a nossa análise. Os resultados do modelo com a medida alternativa podem ser obtidos mediante solicitação aos autores. 


\section{REFERÊNCIAS BIBLIOGRÁFICAS}

AMES, Barry. (2000), The Deadlock of Democracy in Brazil: Interests, Identities and Institutions in Comparative Perspective. Ann Arbor, The University of Michigan Press.

AMORIM NETO, Octavio, COX, Gary W. e MCCUBBINS, Mathew D. (2003), “Agenda Power in Brazil's Câmara dos Deputados, 1989-98". World Politics, vol. 55, no 4, pp. 550-578.

AUSTEN-SMITH, David e RIKER, William H. (1987), “Asymmetric Information and the Coherence of Legislation". American Political Science Review, vol. 81, no3, pp.897-918.

CALVERT, Randall L. (1985), “The Value of Biased Information: A Rational Choice Model of Political Advice". Journal of Politics, vol. 47, no 2, pp. 530-555.

CÂMARA DOS DEPUTADOS. (2004), Regimento Interno da Câmara dos Deputados. Disponível em < http:/ / www2.camara.gov.br/legislacao/regimentointerno.html>.

CAMERON, A. Colin e TRIVEDI, Pravin K. (1998), Regression Analysis of Count Data. New York, Cambridge University Press.

CAMERON, A. Colin e WINDMEIJER, Frank A.G. (1996), “R-Squared Measures for Count Data Regression Models with Applications to Health Care Utilization". Journal of Business and Economic Statistics, vol. 14, pp. 209-220.

CAREY, John. (1998), “Electoral Reform and the Chilean Legislative Party System". Working Paper Series. Centro de Investigación y Doencia Económica, Mexico, D.F.

CARVALHO, Nelson Rojas. (2003), E no Início Eram as Bases: Geografia Política do Voto e Comportamento Legislativo no Brasil. Rio de Janeiro, Revan.

CRAWFORD, Vincent P. e SOBEL, Joel. (1982), "Strategic Information Transmission". Econometrica, vol. 50, no 6, pp.1431-1451.

DUR, Robert e SWANK, Otto H. (2005), "Producing and Manipulating Information". The Economic Journal, vol. 115, pp.185-199.

FIGUEIREDO, Argelina C. e LIMONGI, Fernando. (1999), Executivo e Legislativo na Nova Ordem Constitucional. Rio de Janeiro, Fundação Getulio Vargas Editora.

FIORINA, Morris. (1977), Congress: Keystone of the Washington Establishment. New Haven, $\mathrm{CT}$, Yale University Press.

GILLIGAN, Thomas W. e KREHBIEL, Keith. (1987), “Collective Decision-Making and Standing Committees: An Informational Rationale for Restrictive Amendment Procedures". Journal of Law, Economics, and Organization, vol. 3, no 2, pp. 287-335.

. (1989), "Asymmetric Information and Legislative Rules with a Heterogeneous Committee". American Journal of Political Science, vol. 33, no 2, pp. 459-490.

. (1997), "Specialization Decisions within Committee". Journal of Law, Economics, and Organization, vol. 13, no 2, pp.366-386.

KREHBIEL, Keith. (1991), Information and Legislative Organization. Ann Arbor, The University of Michigan Press.

KRISHNA, Vijay e MORGAN, John. (2001), “A Model of Expertise”. The Quarterly Journal of Economics, vol. 116, no 2, pp. 747-775. 
LEONI, Eduardo. (2002), “Ideologia, Democracia e Comportamento Parlamentar: A Câmara dos Deputados (1991-1998)". Dados, vol. 45, no 3, pp. 361-386.

LONG, J. Scott. (1997), Regression Models for Categorical and Limited Dependent Variables. Thousand Oaks, CA, Sage Publications.

e FREESE, Jeremy. (2003), Regression Models for Categorical Dependent Variables Using Stata. College Station, TX, Stata Press.

MAYHEW, David R. (1974), Congress: The Electoral Connection. New Haven, CT, Yale University Press.

MENEGUELLO, Rachel. (1998), Partidos e Governos no Brasil Contemporâneo (1985-1997). São Paulo, Paz e Terra.

MILGRON, Paul e ROBERTS, John. (1986), "Relying on the Information of Interested Parties". Rand Journal of Economics, vol. 17, no 1, pp.18-32.

MONTENEGRO, Nelson. (2004), Informação na Comissão de Economia, Indústria e Comércio. Trabalho apresentado no 4o Encontro Nacional da Associação Brasileira de Ciência Política, PUC-Rio, Rio de Janeiro, 21-24 julho.

MORROW, James D. (1994), Game Theory for Political Scientists. Princeton, NJ, Princeton University Press.

NICOLAU, Jairo. (2000), “Disciplina Partidária e Base Parlamentar na Câmara dos Deputados no Primeiro Governo Fernando Henrique Cardoso (1995-1998)". Dados, vol. 43, no 4, pp.709-735.

PARKER, Glenn R. (1992), Institutional Change, Discretion, and the Making of Modern Congress: An Economic Interpretation. Ann Arbor, MI, The University of Michigan Press.

PEREIRA, Carlos e MUELLER, Bernardo. (2000), “Uma Teoria da Preponderância do Poder Executivo". Revista Brasileira de Ciências Sociais, vol. 15, no 43, pp. 45-67.

. (2002), "Comportamento Estratégico em Presidencialismo de Coalizão: As Relações entre Executivo e Legislativo na Elaboração do Orçamento Brasileiro". Dados, vol. 45, no 2, pp. 265-301.

PEREIRA, Carlos e RENNÓ, Lúcio. (2001), “O que É que o Reeleito Tem? Dinâmicas Político-Institucionais Locais e Nacionais nas Eleições de 1998 para a Câmara dos Deputados". Dados, vol. 44, no 2, pp. 323-361.

PESSANHA, Charles. (1997), Relações entre os Poderes Executivo e Legislativo no Brasil: 1946-1994. Tese de Doutorado, USP, São Paulo.

POLSBY, Nelson W. (1968), "The Institutionalization of the U.S. House of Representatives". American Political Science Review, vol. 62, no 2, pp. 144-168.

POOLE, Keith e ROSENTHAL, Howard. (1985), “A Spatial Model for Legislative Roll Call Analysis". American Journal of Political Science, vol. 29, no 2, pp. 357-384.

RICCI, Paolo e LEMOS, Leany Barreiro. (2004), “Produção Legislativa e Preferências Eleitorais na Comissão de Agricultura e Política Rural da Câmara dos Deputados". Revista Brasileira de Ciências Sociais, vol. 19, no 55, pp.107-130.

SAMUELS, David J. (2003), Ambition, Federalism, and Legislative Politics in Brazil. New York, Cambridge University Press. 
Fabiano Santos e Acir Almeida

SANTOS, Fabiano. (2003), O Poder Legislativo no Presidencialismo de Coalizão. Belo Horizonte, Editora da UFMG.

SHEPSLE, Kenneth A. (1979), The Giant Jigsaw Puzzle. Chicago, IL, The University of Chicago Press.

e WEINGAST, Barry R. (1995), "Positive Theories of Congressional Institutions", in K. A. Shepsle e B. R. Weingast (eds.), Positive Theories of Congressional Institutions. Ann Arbor, MI, The University of Michigan Press.

VELASCO JR., Licínio. (2005), A Política Pública de Privatização no Presidencialismo de Coalizão Brasileiro. Tese de Doutorado, IUPERJ, Rio de Janeiro.

WEINGAST, B. e MARSHALL, W. (1983), "The Industrial Organization of Congress; or, Why Legislatures, Like Firms Are Not Organized as Markets?" Journal of Political Economy, vol. 96, no 1, pp.132-163.

ZORN, Christopher J.W. (1998), "An Analytic and Empirical Examination of Zero-Inflated and Hurdle Poisson Specifications". Sociological Methods and Research, vol. 26, no 3, pp. 368-400. 


\section{ABSTRACT \\ Informational Theory and Selection of "Rapporteurs" in the Chamber of Deputies}

This article analyzes which factors determine rapporteurship allocation for reviewing bills of law submitted by the Brazilian Executive Branch to the Chamber of Deputies. We argue that the rapporteurs' influence lies in their position as informational agents in the preliminary review committees. Based on this theoretical proposition, we identify the reasons why the first term of the Cardoso Administration witnessed a non-negligible number of rapporteurs from the minority opposition who were designated to report on bills submitted by the Executive. The hypotheses are tested through a statistical model that estimates the number of reports on Executive bills each Deputy obtained during the 1995-98 Legislature by using original data on the characteristics of the Deputies, their parties, and the committees to which they belonged.

Key words: rapporteurs; Chamber of Deputies; informational theory

\section{RÉSUMÉ}

Théorie Informationnelle et Sélection du Rapporteurs dans le Chambre des Députés

Dans cet article, on analyse ce qui détermine la sélection des rapporteurs qui devront examiner des projets issus du pouvoir exécutif à la Chambre des Députés. On soutient que l'influence du rapporteur réside dans sa condition d'agent informationnel des commissions jugeant le mérite. À partir de cette proposition théorique, on repère la raison pour laquelle, pendant le premier gouvernement de Fernando Henrique Cardoso, on a nommé un nombre non négligeable de députés de l'opposition minoritaire pour rapporter des projets du pouvoir exécutif. Le test des hypothèses est fait à l'aide du modèle statistique qui estime le nombre de rapports de projets du pouvoir exécutif obtenus par chaque député pendant la législature 1995-1998, à partir de données d'origine concernant les caractéristiques des députés, leurs partis et les commissions auxquelles ils ont participé.

Mots-clé: rapporteurs; Chambre des Députés; théorie informationnelle 